\title{
Global potential for harvesting drinking water from air using solar energy
}

https://doi.org/10.1038/s41586-021-03900-w

Received: 5 February 2021

Accepted: 11 August 2021

Published online: 27 October 2021

\section{Open access}

Check for updates

\author{
Jackson Lord ${ }^{1 凶}$, Ashley Thomas', Neil Treat', Matthew Forkin'1, Robert Bain ${ }^{2}$, Pierre Dulac $^{3}$, \\ Cyrus H. Behroozi', Tilek Mamutov', Jillia Fongheiser', Nicole Kobilansky', Shane Washburn', \\ Claudia Truesdell' ${ }^{1}$, Clare Lee ${ }^{1}$ \& Philipp H. Schmaelzle ${ }^{1 凶}$
}

Access to safely managed drinking water (SMDW) remains a global challenge, and affects 2.2 billion people ${ }^{1,2}$. Solar-driven atmospheric water harvesting (AWH) devices with continuous cycling may accelerate progress by enabling decentralized extraction of water from air $^{3-6}$, but low specific yields (SY) and low daytime relative humidity $(\mathrm{RH})$ have raised questions about their performance (in litres of water output per day ${ }^{7-11}$. However, to our knowledge, no analysis has mapped the global potential of $\mathrm{AWH}^{12}$ despite favourable conditions in tropical regions, where two-thirds of people without SMDW live ${ }^{2}$. Here we show that AWH could provide SMDW for a billion people. Our assessment-using Google Earth Engine ${ }^{13}$-introduces a hypothetical 1-metre-square device with a SY profile of 0.2 to 2.5 litres per kilowatthour ( 0.1 to 1.25 litres per kilowatt-hour for a 2-metre-square device) at $30 \%$ to $90 \%$ $\mathrm{RH}$, respectively. Such a device could meet a target average daily drinking water requirement of 5 litres per day per person ${ }^{14}$. We plot the impact potential of existing devices and new sorbent classes, which suggests that these targets could be met with continued technological development, and well within thermodynamic limits. Indeed, these performance targets have been achieved experimentally in demonstrations of sorbent materials $s^{15-17}$. Our tools can inform design trade-offs for atmospheric water harvesting devices that maximize global impact, alongside ongoing efforts to meet Sustainable Development Goals (SDGs) with existing technologies.
Ensuring reliable access to safe drinking water for all remains a global challenge, and is formally recognized as an international development priority by 2030 in the United Nations framework for global development priorities, the Sustainable Development Goals 6.1 $1^{18}$. Progress towards this target is measured by the WHO/UNICEF Joint Monitoring Programme (JMP) as the percentage of population using safely managed drinking water (SMDW), where 'safely managed' is defined as "an improved source located on the premises, available when needed and free of fecal and priority chemical contamination"1,2 ${ }^{\prime 2}$ Traditional routes to bring SMDW on premises to currently unserved populations are estimated to cost US\$114 billion per year (from 2015), more than three times the historical financing trend ${ }^{19}$. Moreover, there is increasing global interest in solutions that provide safe drinking water without the environmental consequences of increasing reliance on bottled water and that do not require household-level intervention, which has limited adherence ${ }^{20,21}$. Atmospheric water harvesting (AWH) shows promise to accelerate decentralized access to underserved communities if a cost-effective, off-grid device can be designed and scaled ${ }^{6}$.

Several classes of off-grid AWH designs exist or are being explored $^{8,12,22,23}$, as summarized in Table 1 . AWH devices are categorized by energy source-active devices use external energy sources whereas passive devices rely solely on atmospheric conditions that allow for pre-condensed dew or fog to be harvested. Passive devices are thus limited to geographic niches where dew or fog can be systematically harvested ${ }^{7,12,24}$. Active, sorbent-based AWH devices extract water using primarily solar thermal energy in one of two operational modes: diurnal-mode devices extract at night (when RH is higher) and condense during the day (when solar energy is available) in a single daily cycle, requiring a large sorbent bed. By contrast, continuous-mode devices are not limited to a single daily cycle, and need only hold a small amount of water vapour in-process ${ }^{3,4}$, drastically reducing sorbent mass and device size. This, however, requires extraction at lower RH when solar energy is available, raising questions about performance $\mathrm{e}^{7-11}$. Cooler-condenser devices use work (typically electric energy) to actively cool air below its dew point and collect condensation and-if solar-driven-call for photovoltaic (PV) panels. Unlike solar-thermal devices, solar-driven cooler-condenser devices suffer from a steep loss in electric energy conversion. In the context of specific yield, we use $\mathrm{kWh}$ to denote primary solar energy prior to thermal and other losses, and $\mathrm{kWh}$ pV to denote electrical energy supplied to the device from PV panels after conversion. Unless stated otherwise, ranges of SY refer to RH between $30 \%$ and $90 \%$ at $20^{\circ} \mathrm{C}$.

Here we present an assessment of solar-driven, continuous-mode AWH (SC-AWH) using global data. AWH has much lower SY than

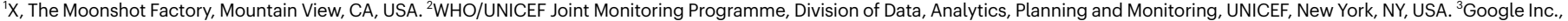

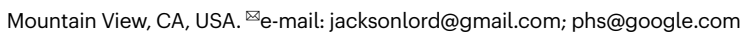


Table 1 | Suitability of household-scale applications by AWH category

\begin{tabular}{|c|c|c|}
\hline & Passive AWH devices & Active AWH devices \\
\hline \multicolumn{3}{|c|}{ Diurnal AWH (single cycle per day) } \\
\hline Device types: & $\begin{array}{l}\text { Dew harvesters } \\
\text { (near-condensed } \\
\text { droplets) }\end{array}$ & Sorption-based \\
\hline Energy Requirements: & None & 0 to $1 \mathrm{l} \mathrm{kWh}^{-1}$ (ref. $^{32}$ ) \\
\hline Size requirements: & $\begin{array}{l}\text { Low mass, but requires } \\
\text { large catchment } \\
\text { surface area }\end{array}$ & $\begin{array}{l}\text { Mass-driven: water } \\
\text { outputs scale proportional } \\
\text { to sorbent mass }{ }^{37}\end{array}$ \\
\hline Global assessment: & Niche potential $^{7}$ & $\begin{array}{l}\text { Wide climate applicability } \\
\text { but mass intensity limits } \\
\text { economic reach }\end{array}$ \\
\hline \multicolumn{3}{|c|}{ Continuous AWH (or multiple cycles per day) } \\
\hline Device types: & $\begin{array}{l}\text { Fog harvesters } \\
\text { (pre-condensed } \\
\text { droplets) }\end{array}$ & $\begin{array}{l}\text { Sorption-based, cooler- } \\
\text { condensers* }\end{array}$ \\
\hline Energy requirements: & None & $\begin{array}{l}\text { Sorption-based: } 0 \text { to } \\
1 \mathrm{l} \mathrm{kWh}{ }^{-1} \text { (ref. }^{32} \text { ); cooler- } \\
\text { condenser: } 2 \text { to } 4 \mathrm{l} \mathrm{kWh}^{-1} \\
\left.\text { (ref. }^{32}\right)^{*}\end{array}$ \\
\hline Sizing requirements: & $\begin{array}{l}\text { Low mass, but requires } \\
\text { large catchment } \\
\text { surface area }\end{array}$ & $\begin{array}{l}\text { Climate-driven and } \\
\text { modular: scaled by } \\
\text { available resource and } \\
\text { solar harvesting area }{ }^{4 *}\end{array}$ \\
\hline Global assessment: & Niche potential $^{7}$ & $\begin{array}{l}\text { Global potential not } \\
\text { previously studied }^{12^{+}}\end{array}$ \\
\hline
\end{tabular}

Select categorization of AWH devices with low or no energy requirements. *Promising categories for low-cost, off-grid devices at household scale. 'There is a gap in the literature on global assessment, which is addressed in this study.

infrastructural water sources such as desalination ${ }^{25}$ (approximately $2001 \mathrm{kWh}^{-1}$ ). However, SC-AWH devices sized to produce sufficient daily drinking water output for an individual or family could address both the water quality and the water access dimensions of SMDW solutions at the household level.

\section{Geography of the global challenge}

To estimate the impact potential of SC-AWH, we first mapped the distribution of the approximately 2.2 billion people without SMDW ${ }^{2}$. Recent studies have used geostatistical techniques to estimate subnational inequalities of safe water and sanitation from a variety of data sources reporting metrics of facility type $\mathrm{e}^{26,27}$. Here we use a deterministic method based exclusively on JMP data on drinking water service levels. In this study, we assume that SC-AWH is for drinking water only and does not replace water for other domestic uses such as hygiene, cooking and sanitation ${ }^{14,28}$.

The overall percentage of the population in regions reported by the JMP at the lowest respective available regional hierarchy is shown in Fig. 1a. This seamless fabric of national and subnational survey regions gives a spatially continuous picture of the global distribution of people living without SMDW. Sub-Saharan Africa contains the highest total number of people without SMDW, in alignment with previous reports ${ }^{2,29}$, followed by regions in South Asia and Latin America.

The regional proportions from Fig. 1a were applied as a linear weight to each pixel of the WorldPop (2017) $1 \mathrm{~km}$-resolution residential population counts image (https://www.worldpop.org). This gives an estimate of the distribution of people without SMDW to a spatial resolution that more closely matches the scales at which climate variables relevant for AWH vary owing to physical geography, such as topography and land cover. The resulting weighted population distribution is shown in Fig. $1 b$.

\section{Geospatial toolset for AWH assessment}

We present a geospatial tool (AWH-Geo) for assessing the global potential for notional SC-AWH devices given available climatic resources. AWH-Geo was built in Google Earth Engine ${ }^{13}$ and is extensible across climate data. For this study, AWH-Geo uses the ERA5-Land climate reanalysis over the 10-year period 2010-2019 (inclusive). ERA5-Land was chosen for its fine resolution ( $9 \mathrm{~km}$ at hourly intervals), global coverage and ability to represent historical synoptic conditions. This period is sufficient to account for interannual variability, although decadal trends are explored in brief in Extended Data Fig. 9. For shorter computation times running their own analysis, the user can adjust the analysis period within the tool.

AWH-Geo takes as input the instantaneous rate of water output as a function of the three dominant environmental variables: (1) global horizontal irradiance from sunlight ( $\mathrm{GHI}\left(\right.$ in $\left.\mathrm{W} \mathrm{m}^{-2}\right)$ ), (2) RH (\%) and (3) air temperature $\left(T\left({ }^{\circ} \mathrm{C}\right)\right.$ ). Secondary climate variables could be incorporated later (for example, downwelling infrared and surface wind speed). We propose an output table with water yield values as a function of binned climate inputs $\mathrm{GHI}, \mathrm{RH}$ and $T$, as a way to connect AWH device models or experimental characterizations with geospatial analyses. Water output can be entered in areal harvesting rates $\left(\right.$ in $\mathrm{h}^{-1} \mathrm{~m}^{-2}$ ) for abstractions, or as the expected yield of a real device with known collection areas (in $\mathrm{l} \mathrm{h}^{-1}$ ). Across all data points of a multi-year climate image time series, AWH-Geo uses the given output table to look up yield values and aggregates water outputs for display as global maps or derived plots. Whereas previous assessments have been limited to relatively small numbers of locations with on-site meteorological data $^{7,30}$ or limited the analysis to a region ${ }^{31}$, the approach presented here is global and spatially continuous. Figure 2 shows a conceptual workflow of AWH-Geo and adjacent processes to produce results in this study.

We first used AWH-Geo to map theoretical upper bounds of solar-driven AWH by constructing output tables from the literature as specific water yields SY (in I kWh ${ }^{-1}$ ). SY is an evaluative metric for AWH sensitive to $\mathrm{RH}^{32}$, and is the inverse of specific energy consumption (SEC), which is commonly used for other water and desalination systems. Resulting maps are overlaid with a dot-density representation of the distribution of people without SMDW for visual comparison in Fig. 3.

Recently, Kim et al. have described the fundamental thermodynamic limits for $\mathrm{AWH}^{33}$. This model gives the minimum thermal energy required (at a given hot-side temperature level) per unit water output of a black box AWH, corresponding to SY values between 5 and $501 \mathrm{kWh}^{-1}$. Kim's thermodynamic limits are mapped in Fig. 3a. Mapping thermodynamic limits is useful to set maximum expectations for SC-AWH output globally and to assess the improvement potential that may exist between existing device performance and fundamental physical limits. Similar analytic approaches have been used to assess condenser-based devices, diurnal devices and dew collectors applied to a specific location or region ${ }^{7,12,30,31}$. The geographic patterns of output closely follow time-averaged humidity values generally, modified by the availability of sunlight. Notably, the results show significant water production potential throughout much of the world, particularly in the tropics.

Next, we mapped the maximum output of two basic design types. Peeters describes the maximum yield for active cooler-condensers ${ }^{32}$, giving SYs of 1-301 $\mathrm{kWh}_{\mathrm{PV}}^{-1}\left(0.2-61 \mathrm{kWh}^{-1}\right)$, plotted using AWH-Geo in Fig. 3b. For sorbent designs, metal organic frameworks (MOFs) and thermo-responsive polymer (TRP) gels ${ }^{17}$ show the highest yields at low and high $\mathrm{RH}$, respectively. Zhao et al. demonstrated exceptional performance of a TRP ${ }^{15}$ at high RH $\left(0.2-9.31 \mathrm{kWh}^{-1}\right.$ (converted to SY by Peeters $\left.{ }^{32}\right)$ ), generally outperforming MOFs (whose reported maximum $^{32}$ SYs are around $11 \mathrm{kWh}^{-1}$ ). Global projections for Zhao's TRP are mapped in Fig. 3c. 


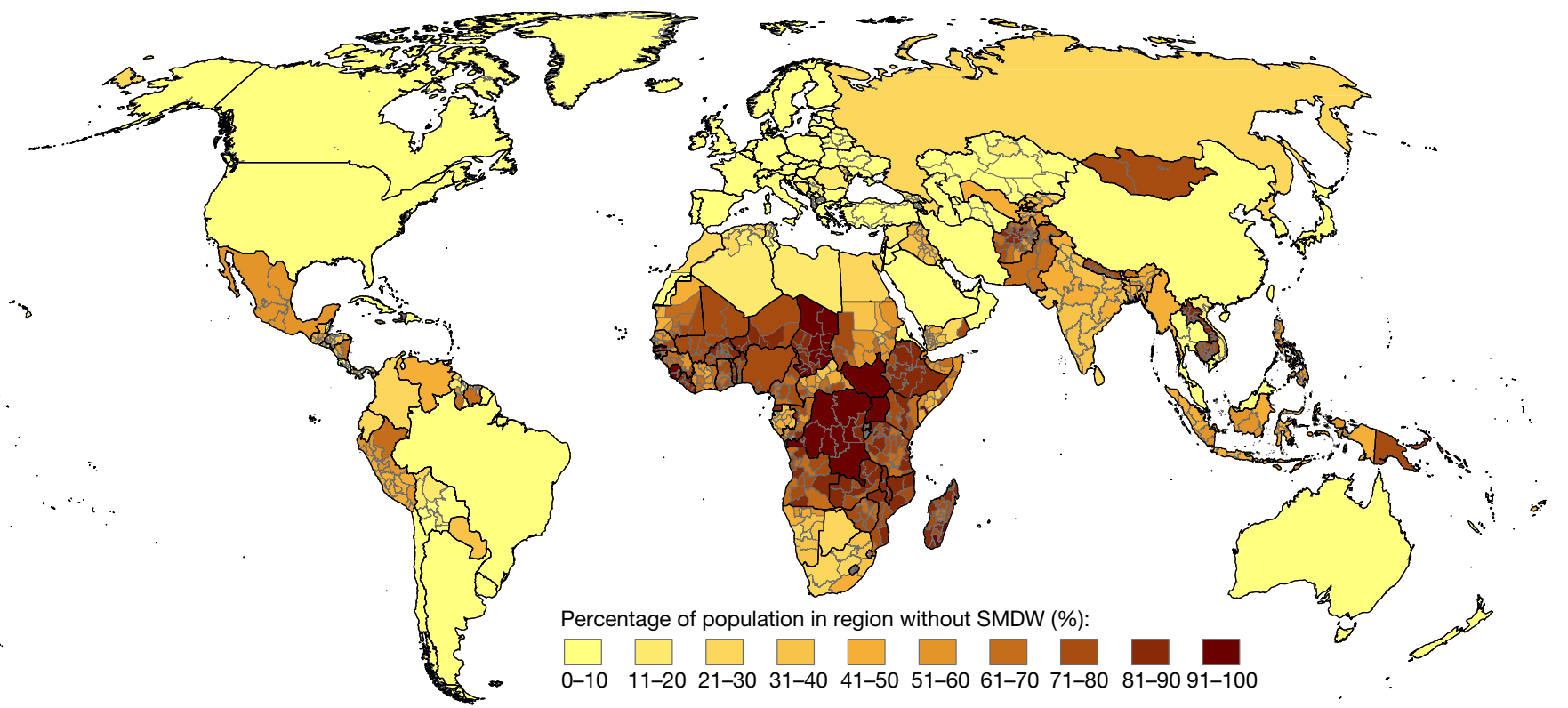

b

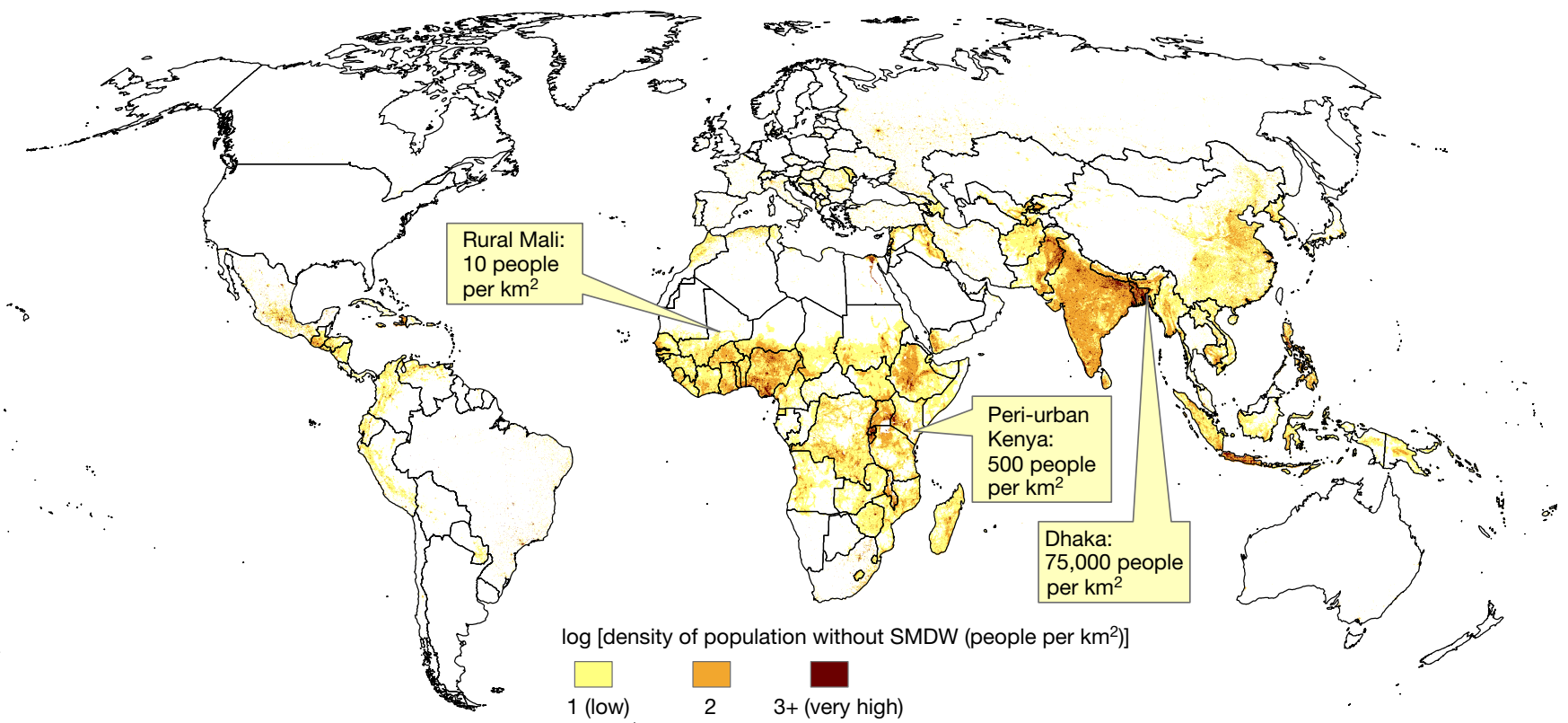

Fig. 1 Geographic distribution of world population without SMDW. a, Percentage share of total population in survey region living without SMDW as reported by the WHO/UNICEFJMP. b, Log population density of people

In addition to annual means, AWH-Geo is capable of deriving metrics useful for analysing seasonal variability of output. Optionally, AWH-Geo exports $90 \%$ availability (P90) values across a set of time windows (Methods).

\section{Assessing the global potential}

Our coincidence analysis calculates the mean hours per day during which $\mathrm{GHI}$ and $\mathrm{RH}$ are simultaneously above parametric thresholds. Fig. 4a maps annual means for such daily coincidence hours for the given threshold pairs, interpreted as the operational hours per day (ophd) for a hypothetical device. Important transition areas between tropical and desert regions show the expected trade-off between sunlight and humidity, which generally vary inversely. Very low RH thresholds of $10 \%$ increase ophd potential by only $1-2 \mathrm{~h}$ from the ophd without SMDW from WorldPop at $1 \mathrm{~km}$ resolution adjusted byJMP proportions at $1 \mathrm{~km}$ resolution. Produced in ArcGIS 10.

at $30 \% \mathrm{RH}$ in arid regions in the Sahel across GHI thresholds, but ophd then falls sharply at higher RH thresholds. This indicates a diminishing return to devices operating below $30 \%$. Coastal areas show promise for consistent 2-4 ophd worldwide above $50 \% \mathrm{RH}$.

Next, we summed the population without access toSMDW segmented by threshold pair using the weighted population image, grouped cumulatively by ophd at whole intervals and shown in Fig. 4b. Inflections of diminishing user potential occur between values of RH between 30 and $50 \%, \mathrm{GHI}$ between 400 and $600 \mathrm{~W} \mathrm{~m}^{-2}$ and ophd between 3 and $5 \mathrm{~h}$. These reflect key spatio-demographic patterns along similar climatic transitions in the tropics, where the bulk of those living without SMDW live-particularly in the tropical savanna of sub-Saharan Africa and the Ganges River Valley in India. A device that could operate above these values has the theoretical potential to serve more than half the world's remaining population lacking access to SMDW. 


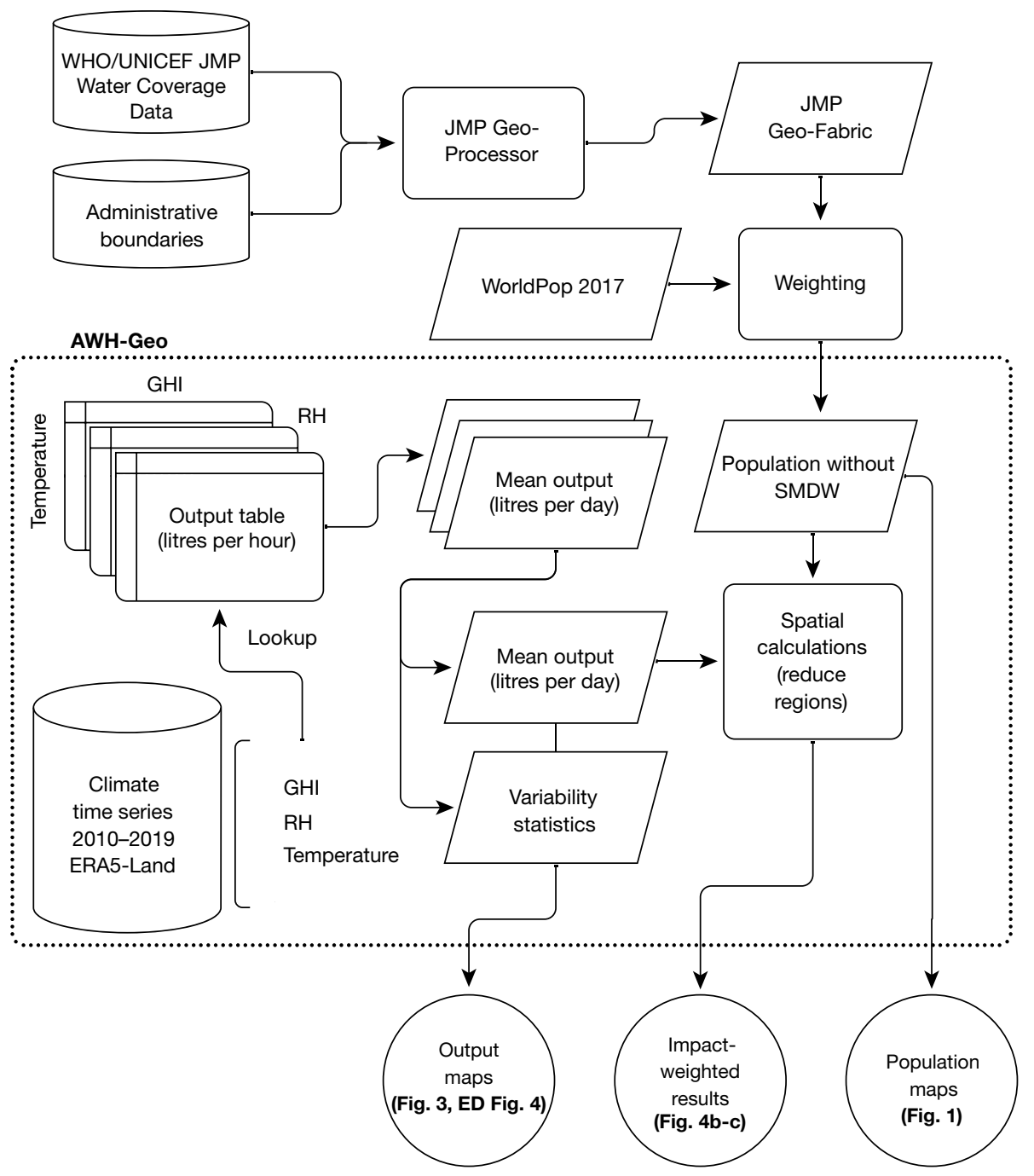

Fig. 2 Data processing workflow of AWH-Geo. Cylinders indicate data stores from Google Earth Engine, the WHO/UNICEFJMP or open online content. Shown are processes (rectangles), geo-images (parallelograms) and outputs (circles).

Next we ran the SY profiles of a collection of SY curves through AWH-Geo, including commercial cooler-condenser devices evaluated by Bagheri ${ }^{34}$ and a data sheet for the SOURCE panel, a sorbent-based device from company SOURCE, formerly known as Zero Mass Water ${ }^{35}$ (ZMW).

Figure $4 \mathrm{c}$ shows resulting outputs normalized by area $\left(\right.$ in $\left.1 \mathrm{~d}^{-1} \mathrm{~m}^{-2}\right)-\mathrm{a}$ performance metric advocated by LaPotin et al. ${ }^{11}$-as a function of the population without SMDW reached. Steep gradients of the human impact of the output mirror those in the coincidence analysis. Linear SY profiles prioritize performance at low $\mathrm{RH}$, but cap output even in resource-rich climates. The target curves are based on hypothetical SY values similar to those characteristic of sorbent or device profiles that reach 1 billion users at an average of $5 \mathrm{Id}^{-1} \mathrm{~m}^{-2}$. Comparing the two target curves demonstrates the expected trade-off between serving more users at low output (linear) and fewer users at high output (logistic).

To further explore trade-offs of the SY curve across different values of $\mathrm{RH}$, we plotted SY values from materials and devices in relation to target curves for reaching $0.5-2.0$ billion people without SMDW at $51 \mathrm{~d}^{-1}$, the approximate daily drinking water requirements of an individual ${ }^{14}$ (Fig. 4d). We based the target curves on a $1 \mathrm{~m}^{2}$ device unless otherwise noted, although water output and SY targets scale linearly with device area in sunlight. To demonstrate this, we plotted a version of the 1.0-billion target based on $2 \mathrm{~m}^{2}$-this doubling of the device area halves the SY requirements for the target impacts. The existing devices both follow approximately linear yields across RH below the 0.5 -billion impact target curves. MOFs and other sorbents show varied results ${ }^{3,36}$, although they remain roughly linear. Zhao's exceptional yields at high RH make up for low performance at low RH (logistic profile), and show the most promise for reaching the largest user base ( 2.0 billion). Figure $4 \mathrm{~d}$ compares material and device performance side-by-side to show the gap between present capabilities and theoretical limits, although real devices will be subject to losses that will prevent them from fully reaching idealized material performance or theoretical limits.

\section{Closing the gap}

This study presents initial conclusions-developing detailed SC-AWH design criteria will require further work. A device with a $1 \mathrm{~m}^{2}$ solar collection area and a SY profile of $0.2-2.51 \mathrm{kWh}^{-1}\left(0.1-1.251 \mathrm{kWh}^{-1}\right.$ for $\left.2 \mathrm{~m}^{2}\right)$ can serve the SMDW needs of about 1 billion people, assuming continuous harvesting of 2-3 $\mathrm{h}$ per day of coincident sunlight of more than $600 \mathrm{~W} \mathrm{~m}^{-2}$ and $\mathrm{RH}$ above $30 \%$. The shape of the SY curve is critical for SC-AWH to take advantage of coincident humidity and solar energy during key periods of the day, typically during morning and evening hours. A trade-off exists between increasing yields at lower $\mathrm{RH}$ (around $30 \%$ ) for those in climate transition zones (northern sub-Saharan Africa and western India), versus focusing on exponentially higher yields in humid regions such as Bangladesh and equatorial regions. 


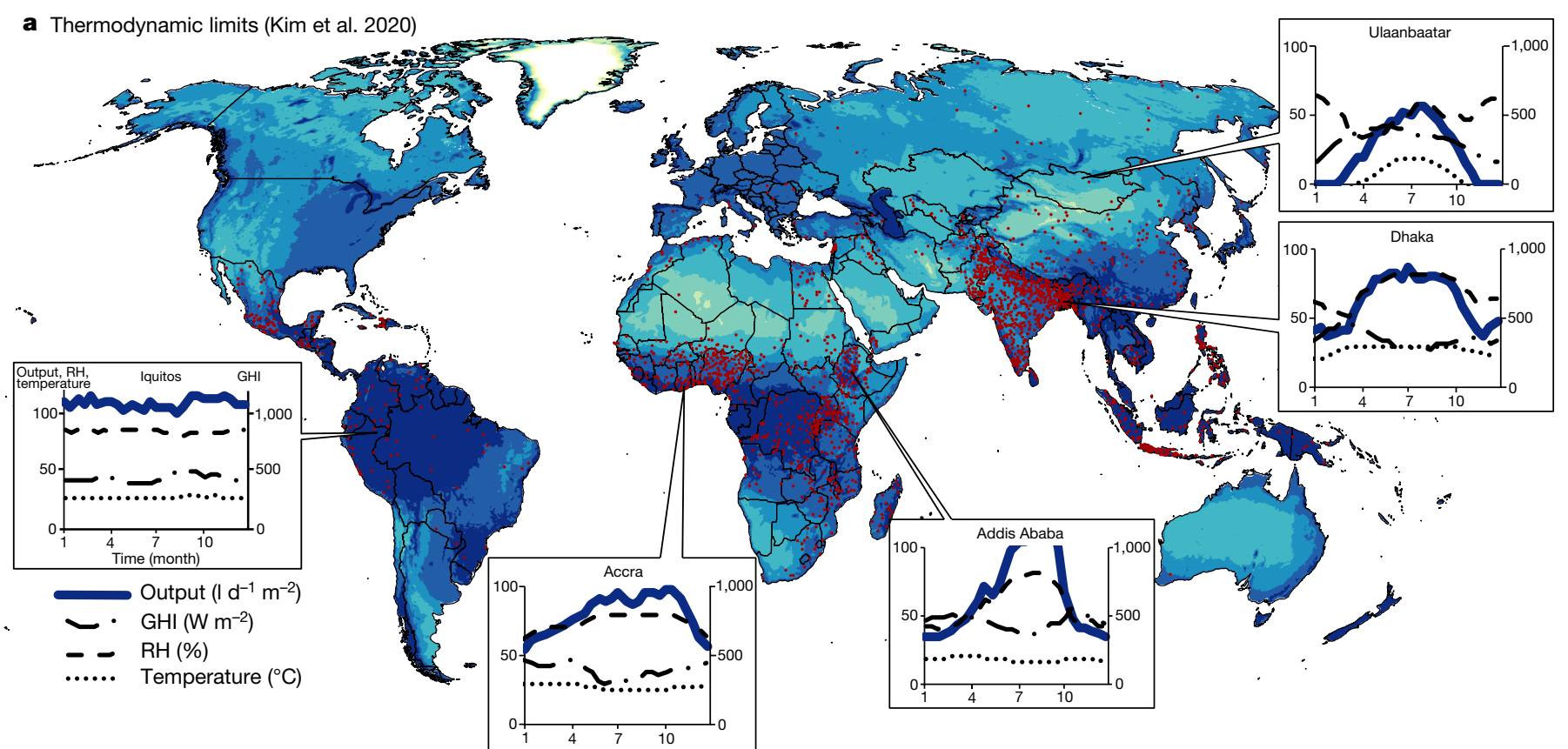

b Cooler-condenser (Peeters et al. 2020)

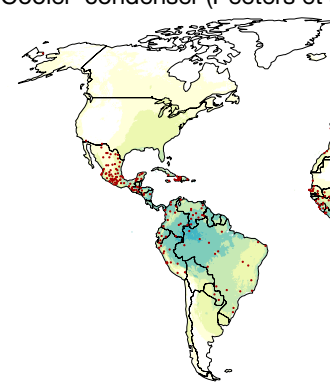

AWH output

$\left(\mathrm{I} \mathrm{d}^{-1} \mathrm{~m}^{-2}\right)$ :

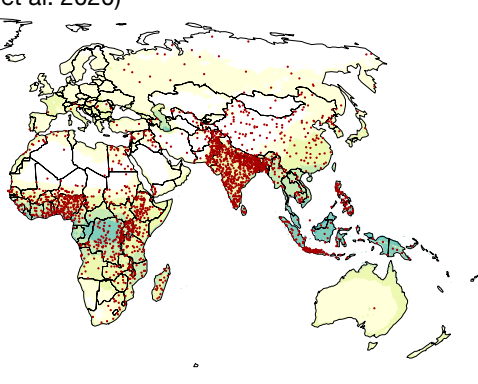

$<2$

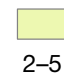

$5-10$

$10 \quad 10-15 \quad 15-20 \quad 20-30$
C Recent thermo-responsive polymer (Zhao et al. 2019)
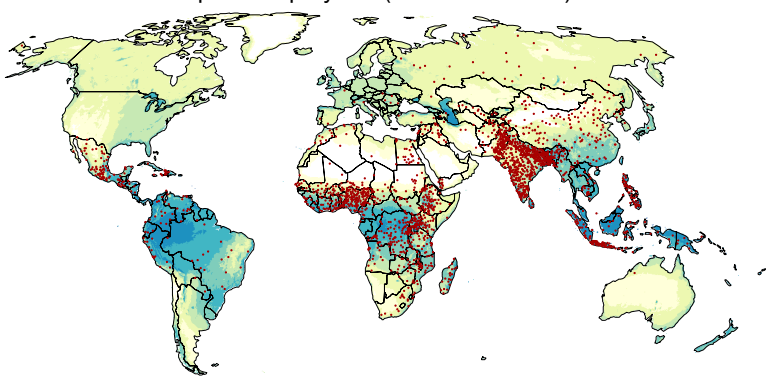

Population without SMDW:
Fig. 3 | Upper bounds water output of solar-driven AWH in relation to global user base. $\mathbf{a}-\mathbf{c}$, Mean daily water output of solar-driven AWH given overall thermodynamic limits of any $\operatorname{process}^{33}\left(T_{\text {hot }}=100^{\circ} \mathrm{C}\right)(\mathbf{a})$, cooler-condenser processes driven by $\mathrm{PV}^{32}$ (b) and example of active sorbent device types (TRP gels from ref. $\left.{ }^{15}\right)(\mathbf{c})$. Callout charts in a show select seasonal profiles in

Researchers and device inventors can cross-reference Fig. 4 when making trade-off decisions between sets of technical specifications and servable regions and people. Recent experiments $s^{4,5,37}$ show rapid improvements in multi-cycled sorption material yield, ranging from 0.1 to more than $8.01 \mathrm{~d} \mathrm{~d}^{-1} \mathrm{~kg}^{-1}$ sorbent in outdoor conditions (RH $10-60 \%, \mathrm{GHI}<1,000 \mathrm{~W} \mathrm{~m}^{-2}$ ), and show inflections in performance along similar ranges as population distributions $\mathrm{s}^{11,31}(\mathrm{RH} 30-50 \%, \mathrm{GHI}$ $400-600 \mathrm{~W} \mathrm{~m}^{-2}$ ). Advancements in device efficiencies from innovative design architectures ${ }^{38}$ and novel high-performance physical sorbents ${ }^{15,17,39-41}$ show promise for increasing SC-AWH output. Individual specific yields from materials experiments or prototypes can be plotted in Fig. $4 \mathrm{~d}$ for benchmarking against target impacts. Validated device performance in outdoor field conditions and published output tables and are needed for global researchers to advance progress of AWH.

The long-term averaged output of an AWH device is an important but limited metric. Seasonal, weekly and diurnal variability in output will influence user adoption and market viability. Some seasonal profiles are explored in Extended Data Figs. 4-8. Short periods of shortfall may be supplemented by storage from previous surpluses. Rainfall collection or alternative sources would be required for seasonal shortfall bi-weekly intervals of mean output and primary climate drivers: $\mathrm{GHI}, \mathrm{RH}$ and temperature. Output (in $\mathrm{d}^{-1} \mathrm{~m}^{-2}$ ) normalized to horizontal device area in sunlight. Real devices will perform below maximum theoretical potentials. Overlaid dot density (red) of 2.2 billion people without SMDW. Placement of dots is spatially arbitrary across the survey region. Produced in ArcGIS 10.

periods, such as those in monsoon climates. Use of multiple water sources and seasonal switching are well established in the literature, although there may be trade-offs with respect to water quality and contamination ${ }^{42,43}$, reinforcing the need for in-depth knowledge of existing water access practices when deploying AWHs, with a focus on household water treatment and safe storage.

The hydro-ecological impacts of AWH for drinking water are probably negligible given the scale of the global atmospheric water budget. Serving all 2.2 billion people without SMDW at $10 \mathrm{Id}^{-1}$ sums to approximately $8 \mathrm{~km}^{3} \mathrm{yr}^{-1}$, a mere $0.20 \%$ of the net water extraction of global cropland $\left(4,000 \mathrm{~km}^{3} \mathrm{yr}^{-1}\right)$ and $0.01 \%$ of total evapo-transpiration over land ${ }^{44}\left(65,500 \mathrm{~km}^{3} \mathrm{yr}^{-1}\right)$.

SC-AWH devices have the potential to be low-cost. Most design architectures have few moving parts (for example, a slowly rotating sorbent wheel $^{8}$ ), and can be constructed from widely available components. Advanced sorbent materials (for example, MOFs or TRP) will need to be mass manufactured to reach cost targets. New high-volume manufacturing methods for $\mathrm{MOFs}^{45,46}$ have the potential to drastically reduce costs.

Technology development is only one part of the complex problem of safe water access; user-centric formative research with a wide variety of 
a

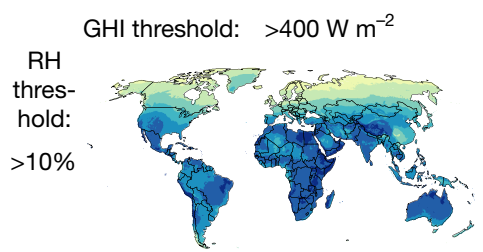

Coincidence of sunlight and humidity above thresholds

$>600 \mathrm{~W} \mathrm{~m}^{-2}$
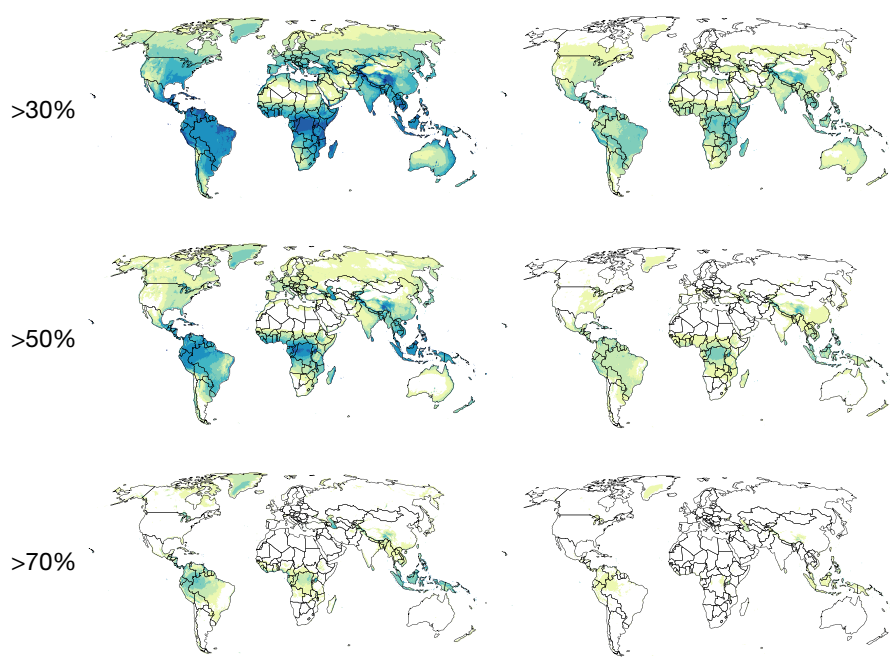

Operational hours per day (Ohpd)

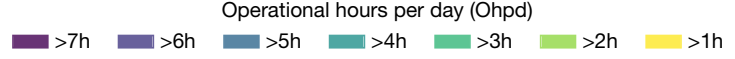

b

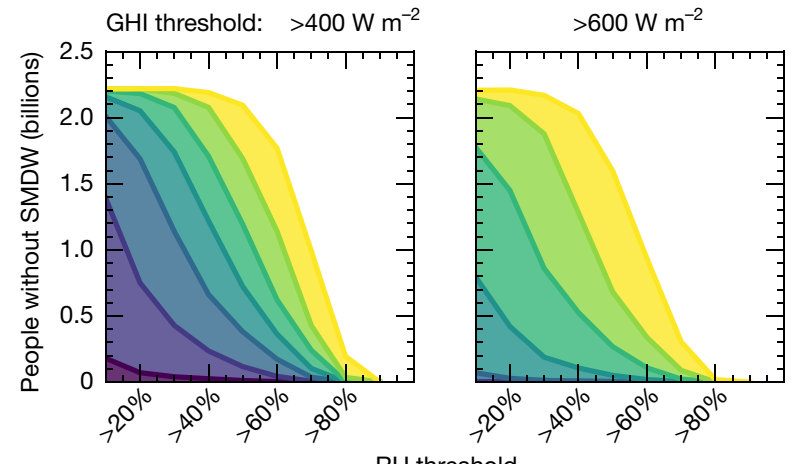

$\mathrm{RH}$ threshold

Fig. 4 | AWH technology parameters in relation to global impact targets. a, b, Geographic distribution (a) and sum (b) of population without SMDW living in areas meeting parametric thresholds relevant to operation of SC-AWH devices. Operational hours per day (Ophd) is the mean daily duration of both sunlight (GHI) and RH thresholds exceeded simultaneously. Usage example: a device requiring more than $5 \mathrm{~h} \mathrm{~d}^{-1}$ of sunlight above $400 \mathrm{~W} \mathrm{~m}^{-2}$ must operate down to $40 \%$ RH to reach approximately 700 million users. c, d, People without SMDW reachable in relation to mean daily output normalized to horizontal device area in sunlight $(\mathbf{c})$ and SY profile (d). Target curves are hypothetical SY profiles capable of providing $5 \mathrm{Id}^{-1}$ for a given solar collection area. Water

end users is critical for ensuring that devices are adopted widely. Similar to bottled water ${ }^{21} \mathrm{SC}$ _AWH devices could paradoxically undermine efforts to develop permanent piped infrastructure. Product affordability and adoption require parallel financial and socio-cultural efforts such as scaling availability of loans, promoting awareness of waterborne disease risk and increasing women's influence over community decisions $\mathrm{s}^{47-49}$.

Our analysis demonstrates that daytime climate conditions may in fact be sufficient for continuous-mode AWH operation in world regions with the highest human need. This assessment suggests that focusing device design criteria on maximum impact and reducing
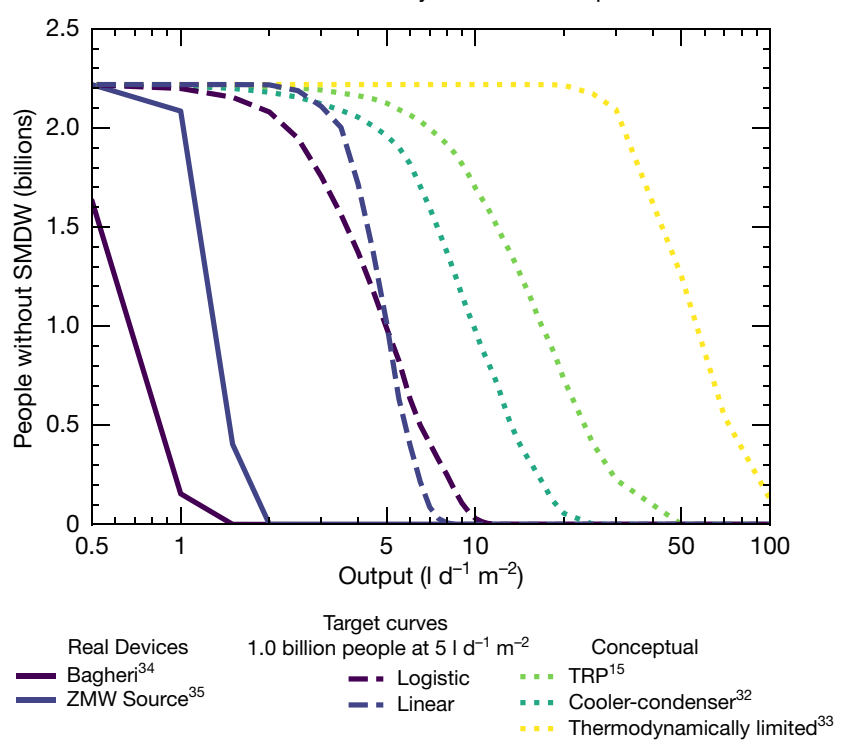

d
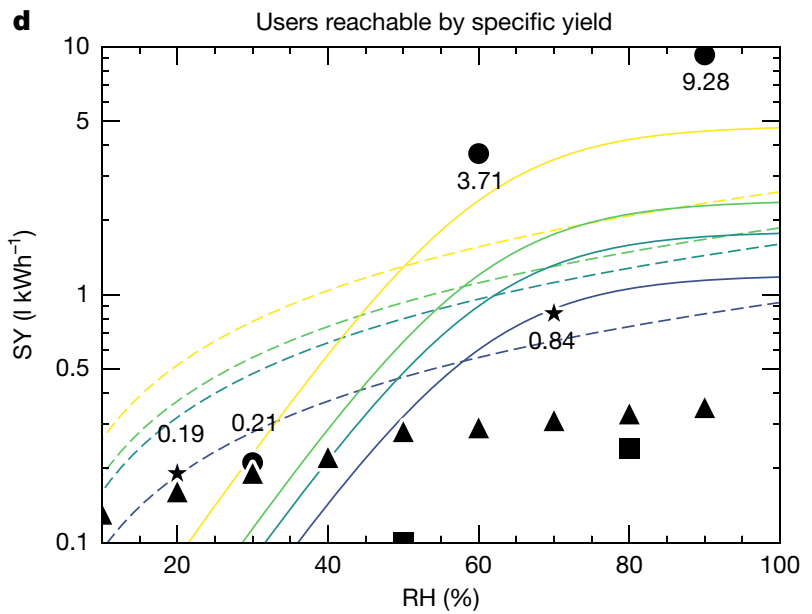

Target (billion people without SMDW)

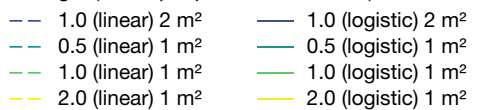
Devices and experiments - Bagheri ${ }^{34}$ $\star$ MOFs and sorbents TRP ${ }^{15}$ ZMW Source ${ }^{35}$

output and SY targets scale linearly with device area in sunlight. For demonstration we therefore show that, for a given $\mathrm{RH}$, doubling the area of a device from $1 \mathrm{~m}^{2}$ to $2 \mathrm{~m}^{2}$ halves the target SY requirement to achieve SMDW for a target population. ZMW Source profile approximated from the manufacturer's technical specifications sheet ${ }^{35}$. Note that the full ZMW panel is approximately $3 \mathrm{~m}^{2}$. Experimental values for MOFs and sorbents are taken from experiments ${ }^{3,36}\left(0.191 \mathrm{kWh}^{-1}\right.$ and $\left.0.84 \mathrm{l} \mathrm{kWh}^{-1}\right)$, and TRP is taken from ref. ${ }^{15}$, all converted as in ref. ${ }^{32}$. Values for the Bagheri device ${ }^{34}$ assume work instead of heat input; therefore photovoltaic efficiencies were applied when converting from GHI. Maps are produced in ArcGIS10.

costs of off-grid production of drinking water at the household scale is a worthwhile effort.

\section{Online content}

Any methods, additional references, Nature Research reporting summaries, source data, extended data, supplementary information, acknowledgements, peer review information; details of author contributions and competing interests; and statements of data and code availability are available at https://doi.org/10.1038/s41586-021-03900-w. 
1. Bain, R., Johnston, R., Mitis, F., Chatterley, C. \& Slaymaker, T. Establishing Sustainable Development Goal baselines for household drinking water, sanitation and hygiene services. Water 10, 1711 (2018).

2. Progress on Drinking Water, Sanitation and Hygiene: 2017 Update and SDG Baselines (World Health Organization and the United Nations Children's Fund, 2017).

3. Hanikel, N. et al. Rapid cycling and exceptional yield in a metal-organic framework water harvester. ACS Cent. Sci. 5, 1699-1706 (2019).

4. Li, R., Shi, Y., Wu, M., Hong, S. \& Wang, P. Improving atmospheric water production yield: enabling multiple water harvesting cycles with nano sorbent. Nano Energy 67, 104255 (2020).

5. Qi, H. et al. An interfacial solar-driven atmospheric water generator based on a liquid sorbent with simultaneous adsorption-desorption. Adv. Mater. 31, 1903378 (2019).

6. Humphrey, J. H. et al. The potential for atmospheric water harvesting to accelerate household access to safe water. Lancet Planet. Health 4, e91-e92 (2020).

7. Gido, B., Friedler, E. \& Broday, D. M. Assessment of atmospheric moisture harvesting by direct cooling. Atmos. Res. 182, 156-162 (2016).

8. Tu, R. \& Hwang, Y. Reviews of atmospheric water harvesting technologies. Energy 201, 117630 (2020).

9. Gould, T. Selling water at $\$ 150 / \mathrm{m}^{3}$ to the world's poorest people - with billionaire backing. Global Water Intelligence vol. 21 (21 May 2020).

10. Kim, H. et al. Adsorption-based atmospheric water harvesting device for arid climates. Nat. Commun. 9, 1191 (2018)

11. LaPotin, A., Kim, H., Rao, S. R. \& Wang, E. N. Adsorption-based atmospheric water harvesting: impact of material and component properties on system-level performance. Acc. Chem. Res. 52, 1588-1597 (2019).

12. Tu, Y., Wang, R., Zhang, Y. \& Wang, J. Progress and expectation of atmospheric water harvesting. Joule 2, 1452-1475 (2018).

13. Gorelick, N. et al. Google Earth Engine: planetary-scale geospatial analysis for everyone. Remote Sens. Environ. 202, 18-27 (2017).

14. Gleick, P. H. Basic water requirements for human activities: meeting basic needs. Water Int. 21, 83-92 (1996).

15. Zhao, F. et al. Super moisture-absorbent gels for all-weather atmospheric water harvesting. Adv. Mater. 31, 1806446 (2019).

16. Kim, H. et al. Water harvesting from air with metal-organic frameworks powered by natural sunlight. Science 356, 430-434 (2017).

17. Matsumoto, K., Sakikawa, N. \& Miyata, T. Thermo-responsive gels that absorb moisture and ooze water. Nat. Commun. 9, 2315 (2018).

18. Global Indicator Framework for the Sustainable Development Goals and Targets of the 2030 Agenda for Sustainable Development (United Nations, 2018).

19. Hutton, G. \& Varughese, M. The Costs of Meeting the 2030 Sustainable Development Goal Targets on Drinking Water, Sanitation, and Hygiene (Water and Sanitation Program, 2016).

20. Brown, J. \& Clasen, T. High adherence is necessary to realize health gains from water quality interventions. PLOS ONE 7, e36735 (2012).

21. Cohen, A. \& Ray, I. The global risks of increasing reliance on bottled water. Nat. Sustain. 1, 327-329 (2018).

22. Wahlgren, R. V. Atmospheric water vapour processor designs for potable water production: a review. Water Res. 35, 1-22 (2001).

23. Zhou, X., Lu, H., Zhao, F. \& Yu, G. Atmospheric water harvesting: a review of material and structural designs. ACS Mater. Lett. 2, 671-684 (2020).

24. Domen, J. K., Stringfellow, W. T., Camarillo, M. K. \& Gulati, S. Fog water as an alternative and sustainable water resource. Clean Tech. Environ. Policy 16, 235-249 (2014)

25. Kim, J., Park, K., Yang, D. R. \& Hong, S. A comprehensive review of energy consumption of seawater reverse osmosis desalination plants. Appl. Energy 254, 113652 (2019).

26. Pullan, R. L., Freeman, M. C., Gething, P. W. \& Brooker, S. J. Geographical inequalities in use of improved drinking water supply and sanitation across Sub-Saharan Africa: mapping and spatial analysis of cross-sectional survey data. PLoS Med. 11, e1001626 (2014).

27. Deshpande, A. et al. Mapping geographical inequalities in access to drinking water and sanitation facilities in low-income and middle-income countries, 2000-17. Lancet Glob. Health 8, e1162-e1185 (2020).

28. Mujwahuzi, M. R. et al. Drawers of Water II: 30 Years of Change in Domestic Water Use \& Environomental Health in East Africa. (International Institute for Environment and Development, 2002).
29. Roche, R., Bain, R. \& Cumming, O. A long way to go-estimates of combined water, sanitation and hygiene coverage for 25 sub-Saharan African countries. PLoS ONE 11, e0171783 (2017).

30. Beysens, D. Estimating dew yield worldwide from a few meteo data. Atmos. Res. 167, 146-155 (2016).

31. Mulchandani, A. \& Westerhoff, P. Geospatial climatic factors influence water production of solar desiccant driven atmospheric water capture devices. Environ. Sci. Technol. 54, 8310-8322 (2020).

32. Peeters, R., Vanderschaeghe, H., Rongé, J. \& Martens, J. A. Energy performance and climate dependency of technologies for fresh water production from atmospheric water vapour. Environ. Sci. Water Res. Technol. 6, 2016-2034 (2020).

33. Kim, H., Rao, S. R., LaPotin, A., Lee, S. \& Wang, E. N. Thermodynamic analysis and optimization of adsorption-based atmospheric water harvesting. Int. J. Heat Mass Transfer 161, 120253 (2020).

34. Bagheri, F. Performance investigation of atmospheric water harvesting systems. Water Res. Industry 20, 23-28 (2018)

35. What Is SOURCE? https://www.source.co/wp-content/uploads/2020/11/SOURCE-TechSpec-Sheet.pdf (accessed June 2021).

36. Wang, J. Y., Wang, R. Z., Wang, L. W. \& Liu, J. Y. A high efficient semi-open system for fresh water production from atmosphere. Energy 138, 542-551 (2017).

37. Hanikel, N., Prévot, M. S. \& Yaghi, O. M. MOF water harvesters. Nature Nanotechnology 15, 348-355 (2020)

38. LaPotin, A. et al. Dual-stage atmospheric water harvesting device for scalable solar-driven water production. Joule 5, 166-182 (2021).

39. Terzis, A. et al. High-frequency water vapor sorption cycling using fluidization of metal-organic frameworks. Cell Rep. Phys. Sci. 1, 100057 (2020).

40. Logan, M. W., Langevin, S. \& Xia, Z. Reversible atmospheric water harvesting using metal-organic frameworks. Sci. Rep. 10, 1492 (2020).

41. Yilmaz, G. et al. Autonomous atmospheric water seeping MOF matrix. Sci Adv 6, eabc8605 (2020).

42. Foster, T. \& Willetts, J. Multiple water source use in rural Vanuatu: are households choosing the safest option for drinking? Int. J. Environ. Health Res. 6, 579-589 (2018).

43. Elliott, M. et al. Addressing how multiple household water sources and uses build water resilience and support sustainable development. npj Clean Water 2, 6 (2019).

44. Oki, T. Global hydrological cycles and world water resources. Science 313, 1068-1072 (2006).

45. Elhenawy, S. E. M., Khraisheh, M., AlMomani, F. \& Walker, G. Metal-organic frameworks as a platform for $\mathrm{CO}_{2}$ capture and chemical processes: adsorption, membrane separation, catalytic-conversion, and electrochemical reduction of $\mathrm{CO}_{2}$. Catalysts 10, 1293 (2020).

46. DeSantis, D. et al. Techno-economic analysis of metal-organic frameworks for hydrogen and natural gas storage. Energy Fuels 31, 2024-2032 (2017).

47. Mohapatra, S. \& Simon, L. Intra-household bargaining over household technology adoption. Rev. Econ. Household 15, 1263-1290 (2017).

48. Barstow, C. K. et al. Designing and piloting a program to provide water filters and improved cookstoves in Rwanda. PLoS ONE 9, e92403 (2014).

49. Daniel, D., Marks, S. J., Pande, S. \& Rietveld, L. Socio-environmental drivers of sustainable adoption of household water treatment in developing countries. npj Clean Water $\mathbf{9}, 12$ (2018).

Publisher's note Springer Nature remains neutral with regard to jurisdictional claims in published maps and institutional affiliations.

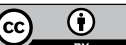

Open Access This article is licensed under a Creative Commons Attribution 4.0 International License, which permits use, sharing, adaptation, distribution and reproduction in any medium or format, as long as you give appropriate credit to the original author(s) and the source, provide a link to the Creative Commons license, and indicate if changes were made. The images or other third party material in this article are included in the article's Creative Commons license, unless indicated otherwise in a credit line to the material. If material is not included in the article's Creative Commons license and your intended use is not permitted by statutory regulation or exceeds the permitted use, you will need to obtain permission directly from the copyright holder. To view a copy of this license, visit http://creativecommons.org/licenses/by/4.0/.

(C) The Author(s) 2021 


\section{Methods}

\section{Water access data processing}

Data on drinking water coverage by region was acquired from the $\mathrm{WHO} /$ UNICEFJMP. The JMP acts as official custodian of global data on water supply, sanitation and hygiene ${ }^{2}$ and assimilates data from administrative data, national census and surveys for individual countries, and maintains a database that can be accessed online through their website. We accessed data tables for national and subnational drinking water service levels from https://washdata.org.

JMP datasets are not geographically linked to official boundary files. We joined the tables to GIS boundaries obtained from the following open-source collections: GADM (https://gadm.org), the Spatial Data Repository of the Demographic and Health Surveys Program of USAID (DHS) and the Global Data Lab of Radboud University (GDL) ${ }^{2,50-53}$. Subnational regions reported by the JMP are unstructured, representing various regional administrative levels (province, state, district and others).

The JMP national and subnational data were joined to GIS boundaries using a custom geoprocessing tool built in Python and ArcGIS 10. The tool joins the available JMP subnational-level survey data to the closest name match of regional boundary names from a merged stack of GADM (admin1, admin2 and admin3), DHS and GDL boundaries worldwide. The JMP national-level survey data is then joined to GADM national (admin0) boundaries for countries which have no subnational data available. Finally, the two boundary-joined datasets (national and subnational) are merged, processed and exported as a seamless global fabric of water-stressed-population data at the highest respective spatial resolutions available (Fig. 1a).

JMP does not report the breakdown between the SMDW and basic service level within subnational regions, and instead reports a combined category called 'at least basic' (ALB). To estimate the SMDW values in subnational regions, a simple cross-multiplication was performed using the splits at the national level:

$$
\mathrm{SMDW}_{\text {subnational }}=\frac{\mathrm{SMDW}_{\text {national }}}{\mathrm{ALB}_{\text {national }}} \times \mathrm{ALB}_{\text {subnational }} \text {, }
$$

where $\mathrm{ALB}_{\text {national }}, \mathrm{ALB}_{\text {subnational }}$ and $\mathrm{SMDW}_{\text {national }}$ are known values.

Validation of the cross-estimation of share of SMDW from ALB for subnational regions was conducted on a reference dataset of nationally representative household surveys that collected data on all criteria for $\mathrm{SMDW}^{54}$, shown in Extended Data Fig. 2. We report regression results of $R^{2}=0.87$ and a standard error of 3.67, indicating a bias which overreports SMDW share and a probable underestimate of people living without SMDW in our study. This discrepancy comes from JMP calculations of SMDW that rely on the minimum value of multiple drinking water service criteria (free from contamination, available when needed and accessible on premise) rather than considering whether individual households meet all criteria for SMDW ${ }^{55}$.

The fraction of population without SMDW was multiplied by residential population values in the WorldPop top-down unconstrained global mosaic population count of 2017 at $1 \mathrm{~km}$ spatial resolution ${ }^{56}$ (https:// www.worldpop.org). WorldPop was accessed online as a TIF image and imported to Google Earth Engine. The year 2017 was chosen to more closely match water access data from JMP. The percentages reported by JMP are probably not uniform within most regions ${ }^{57}$, introducing an unknown error to Fig. 1b, but represent the best estimate available to us given the limitations of these regionally reported data.

\section{Climate input and conversion approximations}

GHI and reference plane. We used $\mathrm{GHI}$ (in $\mathrm{W} \mathrm{m}^{-2}$ ) as solar energy input data. GHI has good availability in climate datasets and introduces the fewest number of assumptions. Since GHI describes the irradiance in a locally horizontal reference plane, this approximation is only exact for devices having a horizontally oriented solar harvesting area. Annually averaged comparisons between horizontal and optimal fixed-tilt panels show negligible differences in direct plus diffuse radiation in tropical latitudes, and ratios below $25 \%$ in locations within $50^{\circ}$ north and south latitudes ${ }^{58}$. Those seeking precise absolute predictions for tilted devices or higher latitudes are encouraged to adapt the provided code to their specific assumptions.

Conversion from SY to AWH output. As discussed in the main text, solar-driven AWH devices typically have one of two predominant energy inputs: thermal (converted directly from incident sunlight on the device) or electrical (from PV). Here, the energy units used to calculate yield in $1 \mathrm{kWh}^{-1}$ are incident solar energy directly from $\mathrm{GHI}$. The various assumptions are made in relation to the reported values based on their source. The thermal limits ${ }^{33}$, target curves, and experimental results reported by $\mathrm{TRP}^{15}$ and MOFs were assumed to have direct (100\%) conversion from sunlight to heat. For the ZMW device, the table provided by the manufacturer accounts for system losses, so the table values were directly converted in our model ${ }^{35}$. For ref. ${ }^{34}$ and the cooler-condenser limits from ref. ${ }^{32}$, which both assume work input instead of heat, we applied a typical PV conversion efficiency of $20 \%$ to convert from sunlight $\mathrm{kWh}(\mathrm{GHI})$ to $\mathrm{kWh}_{\mathrm{PV}}$ (electrical work) input to the device ${ }^{59}$.

Sufficiently short sorbent cycling times. AWH-Geo assumes continuous or quasi-continuous AWH. AWH-Geo considers each 1-h timestep independently and is thus stateless. Aside from edge cases, this is a safe assumption for mass efficient SC-AWH devices, which typically have time constants shorter than $1 \mathrm{~h}$, both for sorbent cycling and for most of the thermal time constants. For devices with longer time constants, batch devices or processes with slow (de)sorption kinetics, this assumption may introduce increased error, and may require further adaptation of the provided code.

\section{Climate time-series calculation}

$\mathrm{AWH}-\mathrm{Geo}$ is a resource-assessment tool for $\mathrm{AWH}$. It consists of a geospatial processing pipeline for mapping water production (in litres per unit time) around the world of any solar-driven continuous AWH device that can be characterized by an output table of the form output $=f(\mathrm{RH}, T, \mathrm{GHI})$.

Output tables show AWH output values in $\mathrm{h}^{-1}$ or $\mathrm{h}^{-1} \mathrm{~m}^{-2}$ across permutations of the 3 main climate variables in the following ranges: $\mathrm{RH}$ between 0 and $100 \%$ in intervals of $10 \%$, GHI between 0 and $1,300 \mathrm{~W} \mathrm{~m}^{-2}$ in intervals of $100 \mathrm{~W} \mathrm{~m}^{-2}$, and $T$ between 0 and $45^{\circ} \mathrm{C}$ in intervals of $2.5^{\circ} \mathrm{C}(2,145$ total output values). The tables are converted into a 3D array image in Google Earth Engine and processed across the climate time-series image collection for the period of interest. Finally, these AWH output values are composited (reduced) to a single time-averaged statistic of interest as an image.

Climate time-series data was acquired from the ERA5-Land climate reanalysis from the European Centre for Medium-Range Weather Forecasts $(\mathrm{ECMWF})^{60}$, accessed from the Google Earth Engine data catalogue. ERA5-Land surface variables were used in 1 -h intervals and $0.1^{\circ} \times 0.1^{\circ}$ (nominal $9 \mathrm{~km}$ ). The 10-year analysis period (2010-2019, inclusive) was used for this work, and represents a period long enough to provide a reasonable correction for medium-term interannual climatic variability.

Climate variables GHI and T were matched to ERA5-Land parameters 'Surface solar radiation downwards' (converted from cumulative to mean hourly) and ' 2 metre temperature' (converted from $\mathrm{K}$ to ${ }^{\circ} \mathrm{C}$ ), respectively. $\mathrm{RH}$ was calculated from the ambient and dew point temperature parameters in a relationship derived from the August-RocheMagnus approximation ${ }^{61}$ rearranged as:

$$
\mathrm{RH}=100 \% \times \frac{\mathrm{e}^{\left(\frac{a T_{\mathrm{d}}}{b+T_{\mathrm{d}}}\right)}}{\mathrm{e}^{\left(\frac{a T}{b+T}\right)}}
$$


where $a$ is 17.625 (constant), $b$ is 243.04 (constant), $T$ is the ERA5-Land parameter ' 2 metre temperature' converted from $\mathrm{K}$ to ${ }^{\circ} \mathrm{C}$, and $T_{\mathrm{d}}$ is the ERA5-Land parameter ' 2 metre dewpoint temperature' converted from $\mathrm{K}$ to ${ }^{\circ} \mathrm{C}$.

Spot validation of the climate parameters and the mapped output was performed manually in Google Earth Engine across several timesteps in 2016 in Ames, Iowa (using the Iowa Environmental Mesonet AMES8 -WSW station ${ }^{62}$ ) and showed insignificant error $(<5 \%)$.

\section{Mapping upper bounds}

Figure 3a maps thermodynamic upper bound outputs for SC-AWH based on an equation from Kim et al. ${ }^{33}$, reproduced below.

$$
\begin{aligned}
\frac{\dot{Q}_{\text {hot, in, min }}}{\dot{m}_{\text {water, out }}}= & {\left[\frac{1}{\omega_{\text {air, in }}-\omega_{\text {air,out }}}\left(e_{\text {air,out }}-e_{\text {air, in }}\right)+e_{\text {water, out }}\right] } \\
& \times\left(1-\frac{T_{\text {ambient }}}{T_{\text {hot }}}\right)^{-1}
\end{aligned}
$$

where $\dot{Q}_{\text {hot, in, min }}$ is the minimum input heat flux (in $\mathrm{W}_{\text {heat }}$ ) required to drive the process, $T_{\text {hot }}$ is the temperature (in K) at which the input heat is delivered, $T_{\text {ambient }}$ is the ambient temperature (in $\mathrm{K}$ ) at which heat is rejected and water and air exit the process, $\dot{m}_{\text {water, out }}$ is the production rate of liquid water by mass, $\omega$ denotes humidity ratios in $\mathrm{kg}$ of water per kg of dry air, $e$ denotes specific exergies, which can be looked up for given temperatures and humidities, subscript air, in denotes ambient air drawn in at $T_{\text {ambient }}$ from which to extract moisture, subscript air,out denotes air exiting the process at $T_{\text {ambient }}$ after extracting some moisture from it, subscript water,out denotes liquid water exiting the process at $T_{\text {ambient }}$ as the desired product.

Parameters not present in this formula, but that are in Kim's underlying derivation: this upper limit is obtained for a small recovery ratio (RR 0) chosen for numerical stability and for reversible process conditions (entropy generation, $S_{\text {gen }}=0$ ).

Kim's model assumes an AWH in which the fundamental energies required are driven by input heat supplied at a temperature $T_{\text {hot }}$. The limit it represents applies independent of the process, number of stages, sorbent choice, and so on, as long as heat drives the process.

We adapt Kim's model to solar energy input, assuming an idealized conversion efficiency from solar irradiance to usable heat of $100 \%$. This idealization retains a robust upper bound without bringing in additional parameters. Literature values for theoretical sun-to-heat efficiency limits range from $>99.99$ to $95.80 \%$ for thermal absorbers, depending on the level of angular selectivity ${ }^{63}$.

Rearranged, Kim's model yields

$$
\begin{aligned}
\frac{\dot{V}_{\text {water,out }}}{A} \leq & E_{\mathrm{GHI}} \times\left(1-\frac{T_{\text {ambient }}}{T_{\text {hot }}}\right) \\
& \times\left[\frac{1}{\omega_{\text {air,in }}-\omega_{\text {air,out }}}\left(e_{\text {air, out }}-e_{\text {air, in }}\right)+e_{\text {water, out }}\right]^{-1} \times \frac{1}{\rho_{\text {water }}}
\end{aligned}
$$

where, in addition, $\dot{V}_{\text {water, out }}$ is the production rate of liquid water by volume, $A$ is the area harvesting sunlight (see approximation section below), $E_{\mathrm{GHI}}$ is $\mathrm{GHI}$ in $\mathrm{W}_{\text {sun }} \mathrm{m}^{-2}$, and $\rho_{\text {water }}$ is the density of water.

This is now a function of the three key climate variables: $\mathrm{GHI}$ (in the first term), ambient temperature (in the second and hidden in the third term) and $\mathrm{RH}$ (entering the third term). This was converted to an output table and processed through the AWH-Geo pipeline and presented in Fig. 3a. While this can be run for any choice of parameter $T_{\text {hot }}$, we present figures here for $T_{\text {hot }}=100^{\circ} \mathrm{C}$, a temperature still achievable in low-cost (non-vacuum) practical devices without tracking or sunlight concentration. Higher driving temperatures increase the upper bound for water output. For the limits analysis, values of $\mathrm{RH}$ above $90 \%$ are clamped to prevent unrealistically high theoretical outputs as Kim's equation goes to infinity at $100 \% \mathrm{RH}$. A further assumption is made that new ambient air is efficiently refreshed.

Figure $3 \mathrm{~b}$ maps the maximum yield for active cooler-condensers without recuperation of sensible heat-all given work input and an optimum coefficient of performance of the cooling unit at a condenser temperature that maximizes specific yield as modelled by Peeters ${ }^{32}$, which we digitized from their fig. 11. Peeters chose to set yield to zero whenever frost formation would be expected on the condenser. Since Peeters assumes work input, we convert from solar energy (GHI) to $\mathrm{kWh}_{\mathrm{PV}}$ as discussed above.

Figure 3c maps Zhao's experimental results from a TRP using a logistic regression curve fit to their reported SYs of $0.21,3.71$ and $9.281 \mathrm{kWh}^{-1}$ at 30,60 and $90 \% \mathrm{RH}$, respectively ${ }^{15}$. The terms of the curve fit are reported in the next section.

Custom yellow to blue map colours are based on www.ColorBrewer. org, by C. A. Brewer, Penn State ${ }^{64}$.

\section{Specific yield and target curves}

Two simple characteristic equations, linear and logistic, were used to fit a limited set of SY and RH pairs from laboratory experiments or reported values and plotted through AWH-Geo using calculated output tables. Hypothetical curves of similar form whose terms were adjusted iteratively in AWH-Geo to goal-seek a target output $\left(5 \mathrm{I} \mathrm{d}^{-1}\right)$ and user base, and are reported here (for $1-\mathrm{m}^{2}$ devices). In the following equations, $\mathrm{RH}$ in \% is taken as a fraction (for example $55 \%$ is equivalent to 0.55 ).

The linear target curve is a simple linear function which crosses the $y$-axis at zero:

$$
\mathrm{SY}(\mathrm{RH})=a \times \mathrm{RH}
$$

where $a$ is set to $1.60,1.86$ and $2.60 \mathrm{~L} / \mathrm{kWh}$ to reach targets of $0.5,1.0$, and 2.0 billion people without SMDW, respectively, and $\mathrm{RH}$ is input $\mathrm{RH}$ (fractional).

The logistic target curve is a logistic function:

$$
\mathrm{SY}(\mathrm{RH})=\frac{L}{1+\mathrm{e}^{-k\left(\mathrm{RH}^{\left.-\mathrm{RH}_{0}\right)}\right.}}
$$

where $L$ is set to $1.80,2.40$ and $4.80 \mathrm{~L} \mathrm{kWh}^{-1}$ to reach targets of $0.5,1.0$ and 2.0 billion people without SMDW, respectively, $k$ is the growth rate set to 10.0, and $\mathrm{RH}$ and $\mathrm{RH}_{0}$ are input $\mathrm{RH}$ (fractional), and 0.60, respectively.

The SY values reported by Zhao for TRPs (which they term 'SMAG') were fit to a logistic function of the same form with the following parameters: $L$ set to $9.81 \mathrm{~L} \mathrm{kWh}^{-1}, k$ set to 11.25 and $\mathrm{RH}_{0}$ set to 0.645 .

The resulting fitted SY profile is expanded into an output table. As with all reports providing SY values instead of full output tables, this forces an assumption of linearity in heat rate (approximately equal to $\mathrm{GHI}$ ), which may introduce error at lower GHI levels. Zhao reports SY of the TRP material is consistent across temperature below $40{ }^{\circ} \mathrm{C}$-the material's lower critical solution temperature-above which its performance drops precipitously. Accordingly, we set the SY to $01 \mathrm{kWh}^{-1}$ for temperatures $\geq 40^{\circ} \mathrm{C}$ in the output table.

Bagheri reported performance of three existing AWH devices across several climate conditions using an 'energy consumption rate' in $\mathrm{kWh} / \mathrm{L}$, which can be considered to be the SEC, and the simple reciprocal of SY. Instead of fitting a logistic curve to the reciprocals, we fit an exponential function to the average SEC of the three devices in conditions above $20^{\circ} \mathrm{C}$ of the equation:

$$
\operatorname{SEC}(\mathrm{RH})=9.03 \mathrm{e}^{-2.99 R H}
$$

where SEC is specific energy consumption in $\mathrm{kWh}_{\mathrm{PV}} \mathrm{l}^{-1}$ and $\mathrm{RH}$ is fractional. 
This was applied to $\mathrm{RH}$ and taken as reciprocal in an output table and run through AWH-Geo. Since Bagheri reports the equivalent of $\mathrm{kWh}_{\mathrm{PV}}$, we scale to adapt to $\mathrm{GHI}$ input with a photovoltaic conversion efficiency as discussed above.

For performance of the ZMW device (the company's $\sim 3 \mathrm{~m}^{2}$ SOURCE Hydropanel), we used values from the panel production contour plot in the technical specification sheet available from the manufacturer's website $^{35}$. The decision for inclusion was made owing to the importance as an early example of a SC-AWH product with commercial intent. Values in I per panel per day were taken at each $10 \% \mathrm{RH}$ step at $5 \mathrm{kWh} \mathrm{m}^{-2}$, assumed to represent $\mathrm{kWh} \mathrm{m} \mathrm{m}^{-2} \mathrm{~d}^{-1}$, and divided by $15 \mathrm{kWh}\left(\sim 3 \mathrm{~m}^{2} \times 5 \mathrm{kWh} \mathrm{m}^{-2}\right)$ to convert to $S Y$ in $I \mathrm{kWh}^{-1}$. From the resulting SY curve, an output table was generated and processed with AWH-Geo.

\section{Coincidence analysis and population sums}

The coincidence analysis was run through AWH-Geo across 70 threshold pairs given the full permutation set of RH from 10 to $100 \%$ and $\mathrm{GHI}$ from 400 to $700 \mathrm{~W} \mathrm{~m}^{-2}$ threshold intervals, using binary image time series. The resulting mean multiplied by 24 represents average hours per day thresholds are met simultaneously, giving ophd. Below is a functional representation of this time-series calculation:

$\left\langle\left(\mathrm{RH}_{t, \mathrm{px}}>\mathrm{RH}_{\text {threshold }}\right) \& \&_{\text {simultaneous }}\left(\mathrm{GHI}_{t, \mathrm{px}}>\mathrm{GHI}_{\text {threshold }}\right)\right\rangle_{\text {time average }}$

where $\mathrm{RH}_{t, \mathrm{px}}$ is the $\mathrm{RH}$ in the map pixel px at time $t, \mathrm{RH}_{\text {threshold }}$ is the threshold of $\mathrm{RH}$ above which the device is assumed to operate, $\mathrm{GHI}_{t, \mathrm{px}}$ is the $\mathrm{GHI}$ in the map pixel px at time $t$, and $\mathrm{GHI}_{\text {threshold }}$ is the threshold of $\mathrm{GHI}$ above which the device is assumed to operate.

The population calculation was then conducted on these images in Google Earth Engine.

Zonal statistics were performed on the mean ophd images as integers (0-24) using a grouped image reduction (at 1,000-m scale) summing the population integer counts on the population without SMDW distribution image created previously (derived from WorldPop). This reduction was performed at $1,000 \mathrm{~m}$. Validation was performed in Google Earth Engine on single countries within single ophd zones and showed insignificant error $(<2 \%)$. The population results were collected as a table (feature collection) and population was summed cumulatively within stacked ophd zones. These were exported to R for plotting in Fig. $4 \mathrm{~b}$.

To assess the sensitivity of results to the choice of climate and population dataset, we performed a coincidence analysis (Fig. 4b) with alternative datasets and provide those results in Extended Data Fig. 1.

As an alternative climate dataset to ERA-5 $(1 \mathrm{~h}, 9 \mathrm{~km})$, we used NASA's Global Land Data Assimilation System (GLDAS) 2.1 at $0.25^{\circ} \times 0.25^{\circ}$ spatial resolution (nominally $30 \mathrm{~km}$ ) and $3 \mathrm{~h}$ temporal resolution ${ }^{65}$ during the period concurrent with the main results, 2010-2019. As an alternative population dataset to WorldPop 2017, we used Oak Ridge National Laboratory's LandScan 2017 ambient population counts at $1 \mathrm{~km}$ spatial resolution ${ }^{66}$. Two results comparisons were calculated: (1) GLDAS calculated with WorldPop 2017 for direct comparison of climate data input, and (2) GLDAS calculated with LandScan for comparison of climate and population dataset substitution.

The intercomparisons suggest there is negligible sensitivity to the population dataset used, but substantial and systematic sensitivity to the climate dataset used, while all intercomparisons agree in main features and qualitative conclusions. The spatially and temporally $(3 \times)$ coarser GLDAS dataset consistently results in lower predictions of water output and impact than the finer ERA- 5 climate reanalysis. We speculate that the 3-h timesteps of GLDAS are insufficient to capture the performance-critical humidity and GHI dynamics throughout the day (probably morning and evening hours), and, similarly, the $30-\mathrm{km}$ pixels are insufficient to resolve fine-scale climate patterns driven by topographic and other microscale physiographic effects. This illustrates the importance of using high-resolution climate datasets.

\section{Variability statistics of AWH output}

To go beyond annual averages and study availability, we introduce a set of metrics we named moving average density 90th percentile (MADP90).

The MADP90-t represents a device's average output rate $\left(\mathrm{l} \mathrm{d}^{-1} \mathrm{~m}^{-2}\right)$ that will be exceeded for $90 \%$ of periods lasting $t$ days at the given location. MADP90 is calculated from the derived P90 value across a probability density function (PDF) of daily mean output during each $t$-day window in the time series (2010-2019). The result is a scalar that can be mapped spatially. Moving-window periods of 1, 7, 30, 60, 90 and 180 days were examined in this study. MADP90-results are available as additional results and map layers in AWH-Geo.

Extended Data Fig. 3 provides an example set of PDFs for a location in southwest Tanzania. Each of the P90 values correspond to a version of the MADP90 metric corresponding to a moving window period. The P90 value naturally increases with $t$ in most geographic locations as the PDF tightens its dispersion about the natural (P50) mean.

\section{Data availability}

The software and datasets generated during and/or analysed during the current study are available in the following repositories. GitHub: https:// github.com/AWH-GlobalPotential-X/AWH-Geo; Figshare: https://doi. org/10.6084/m9.figshare.c.5642992.v1;JMP Geoprocessor package (Python and ArcGIS geoprocessing model); JMP Geofabric dataset (shapefile); population without SMDW image data layer (geoTiff); upper limit AWH output data layers (geoTiff); coincidence analysis results data tables (Sheets); and output tables used in this study (Sheets). Source data are provided with this paper.

\section{Code availability}

The software used during the current study is available as follows. GitHub: https://github.com/AWH-GlobalPotential-X/AWH-Geo; AWH-Geo application: processor and output viewer with source code; population and result data processing scripts.

50. Smits, J. \& Permanyer, I. The Subnational Human Development Database. Sci. Data 9, 190038 (2019).

51. GADM v3.6. Global Administrative Areas 2020 (University of California, Berkeley, 2020); https://gadm.org

52. Spatial Data Repository, The Demographic and Health Surveys Program (USAID, 2020) https://spatialdata.dhsprogram.com

53. GDL v3.7.0. Global Data Lab Area Database 2020 (Institute for Management Research, Radboud University, 2020); globaldatalab.org

54. Integrating Water Quality Testing into Household Surveys: Thematic Report on Drinking Water (United Nations Children's Fund and World Health Organization, 2O2O).

55. Bain, R., Johnston, R., Khan, S., Hancioglu, A. \& Slaymaker, T. Monitoring drinking water quality in nationally representative household surveys in low- and middle-income countries: Cross-sectional analysis of 27 Multiple Indicator Cluster Surveys 2014-2020. Environ. Health Perspect. 129, 97010 (2021).

56. Lloyd, C. T. et al. Global spatio-temporally harmonised datasets for producing high-resolution gridded population distribution datasets. Big Earth Data 3, 108-139 (2019).

57. Bain, R., Johnston, R. \& Slaymaker, T. Drinking water quality and the SDGs. npj Clean Water 3, 37 (2020).

58. Jacobson, M. Z. \& Jadhav, V. World estimates of PV optimal tilt angles and ratios of sunlight incident upon tilted and tracked PV panels relative to horizontal panels. Solar Energy 169, 55-66 (2018).

59. Champion photovoltaic module efficiency chart. National Renewable Energy Laboratory https://www.nrel.gov/pv/assets/pdfs/champion-module-efficiencies.20200708.pdf (2020).

60. Muñoz Sabater, J. ERA5-Land Hourly Data from 1981 to Present. Copernicus Climate Change Service (C3S) Climate Data Store (CDS) https://doi.org/10.24381/cds.e2161bac (2019).

61. Alduchov, O. A. \& Eskridge, R. E. Improved Magnus` form approximation of saturation vapor pressure. J. Appl. Meteorol. Climatol. 35, 601-609 (1996).

62. Iowa Environmental Mesonet (lowa State University, 2020); https://mesonet.agron.iastate. edu/

63. Blanco, M. J., Martín, J. G. \& Alarcón-Padilla, D. C. Theoretical efficiencies of angular-selective non-concentrating solar thermal systems. Solar Energy 76, 683-691 (2004).

64. Brewer, C. A. ColorBrewer2. http://www.ColorBrewer.org (2020). 
65. Beaudoing, H., Rodell, M. GLDAS Noah Land Surface Model L4 Monthly $0.25 \times 0.25$ Degree V2.1 (Goddard Earth Sciences Data and Information Services Center, 2020); https://doi.org/10.5067/SXAVCZFAQLNO

66. Rose, A. N., McKee, J. J., Urban, M. L. \& Bright, E. A. LandScan 2017 (Oak Ridge National Laboratory, 2018).

Acknowledgements We acknowledge contributions from many colleagues, including $A$. Aron-Gilat, D. Youmans, G.L. Whiting, M. Eisaman, S. Lin, J. Sargent, S. McAlister, S. Chariyasatit, B. Dixon, E. St Jean Duggan, F. Carlsvi, K. Stratton, M. McCoy, R. Hessmer, J. Hanna, H. Riley, P. Watson, M. Day, B. Quintanilla-Whye, A. Ramadan, A. Little and D. Moufarege. We thank the WHO/UNICEF JMP team for guidance on drinking water service estimates, in particular T.

Slaymaker, R. Johnston and F. Mitis; the team at Google Earth Engine, in particular S. Ilyushchenko, S. Agarwal, T. Erickson, N. Gorelick, M. Hancher, M. Dixon, M. DeWitt, J. Conkling, N. Clinton, K. Reid, E. Engle, W. Rucklidge and the entire Earth Engine development community for advice; C. Caywood for code review; B. Schillings and J. Gagne for internal sponsorship at X. Funding was provided by Google LLC.

Author contributions P.H.S. and J.L. conceived the study. J.L., P.D., T.M. and N.T. performed analysis and plots. A.T., N.T., J.L., P.H.S., R.B. and C.H.B. developed arguments. J.L., P.H.S., A.T. and R.B. wrote the paper. This study was conducted as a subset of a larger effort at X, led by P.H.S., M.F, N.T and A.T, to develop a household AWH as a commercial product, which informed the current study: M.F., N.T. and S.W. led prototype development and experimentation, C.H.B. conducted physical modelling, M.F., S.W., C.T., C.L. and others built devices and conducted experiments, A.T., J.F. and N.K. conducted market and user research.

Competing interests We disclose the following potential competing interests. This work was funded by X, The Moonshot Factory (formerly known as Google[x]). X is a part of Alphabet. Both are for-profit entities. $\mathrm{X}$ has filed for patent protection for water-from-air devices, on which multiple authors are listed as inventors. Water-from-air devices may represent significant commercial opportunities upon meeting certain metrics. This work may be pursued further in various ways, including as a possible spinout company in which one or more authors may become founders, officers, shareholders, employees or otherwise involved with a financial interest.

Additional information

Supplementary information The online version contains supplementary material available at https://doi.org/10.1038/s41586-021-03900-w.

Correspondence and requests for materials should be addressed to Jackson Lord or Philipp H. Schmaelzle.

Peer review information Nature thanks Marisa Escobar and the other, anonymous, reviewer(s) for their contribution to the peer review of this work. Peer reviewer reports are available. Reprints and permissions information is available at http://www.nature.com/reprints. 
a

GHI Threshold $\left(\mathrm{W} / \mathrm{m}^{2}\right):>400$

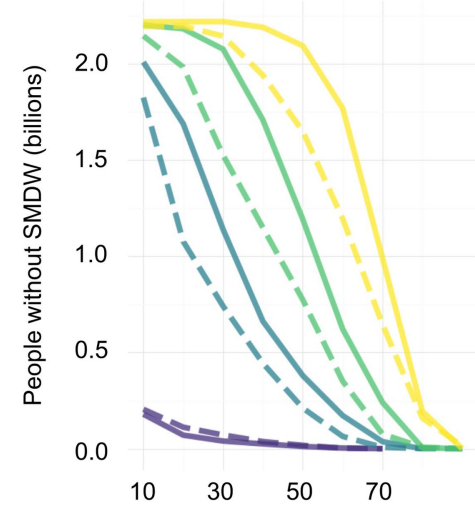

b

GHI Threshold $\left(\mathrm{W} / \mathrm{m}^{2}\right):>400$

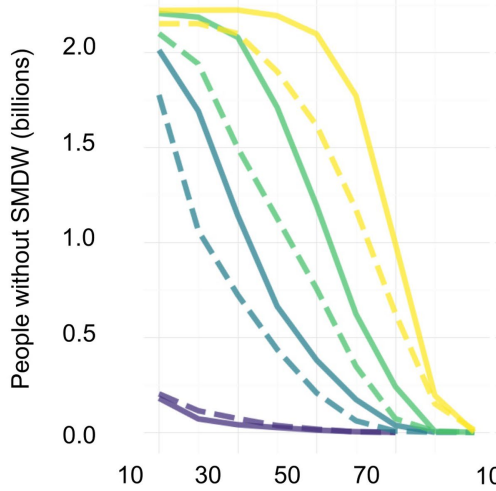

Results Comparison to Dataset GLDAS

$>500$

$>600$

$>700$
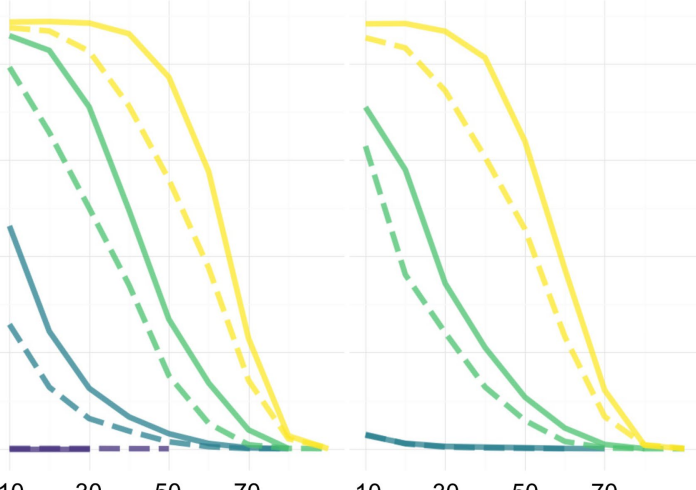

30

70

opH/d

7

5

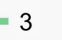

Dataset

-ERA5-Land - - . GLDAS

Results Comparison to Dataset GLDAS_LandScan

$>500$

$>600$

$>700$
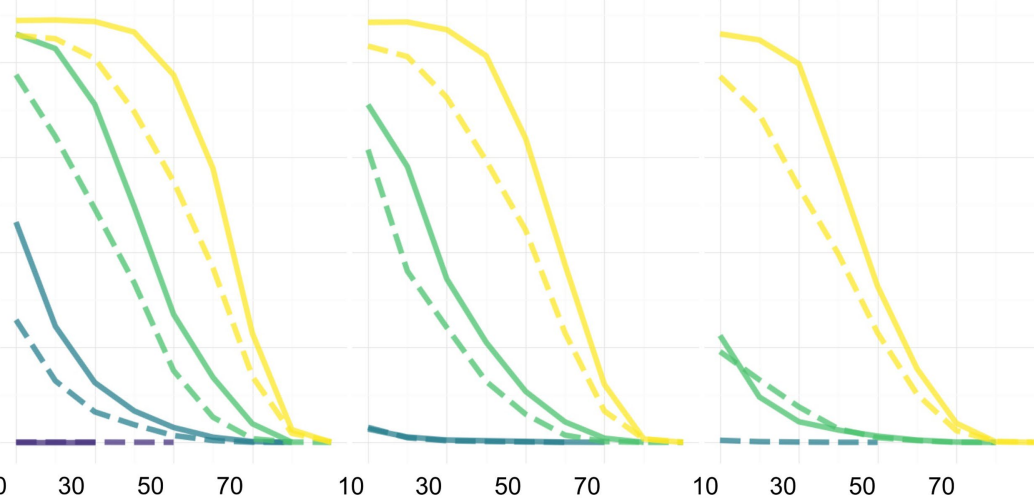

rH Threshold (\%)

\section{opH/d}

7

Dataset

ERA5-Land- - · GLDAS_LandScan

Extended Data Fig. 1 | Comparison of coincidence analysis results to input datasets. Main results from coincidence analysis (Fig. 4b, people without SMDW served by $o p H / d$ of coincident climate threshold) with ERA5-Land and WorldPop 2017 datasets compared with results from (a) GLDAS 2.1 climate and
WorldPop 2017 population, and (b) GLDAS 2.1 climate and LandScan 2017 population datasets. Operational hours per day $(\mathrm{opH} / \mathrm{d})$ shown across global horizontal irradiance $(G H I)$ and relative humidity $(r H)$ thresholds. 


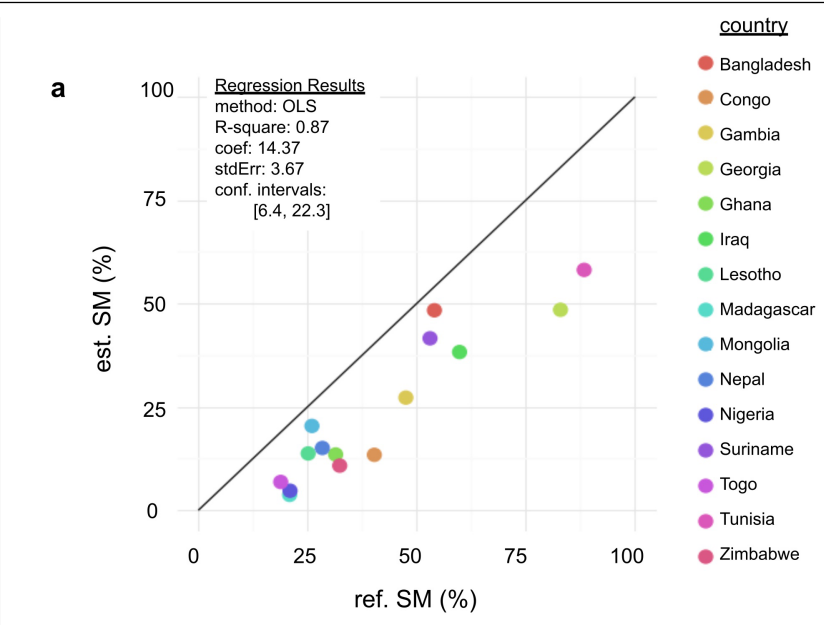

b

\begin{tabular}{ccccccc}
\cline { 3 - 6 } b & & \multicolumn{5}{c}{$\mathrm{rH}(\%)$} \\
\cline { 3 - 7 }$\left(\mathrm{W} / \mathrm{m}^{2}\right)$ & $\mathrm{opH} / \mathrm{d}$ & 10 & 30 & 50 & 70 & 90 \\
\hline & & \multicolumn{5}{c}{ People without SMDW (millions) } \\
\cline { 3 - 7 } 400 & 1 & 3,045 & 3,047 & 2,887 & 1,348 & 1 \\
400 & 3 & 3,027 & 2,868 & 1,646 & 326 & 0 \\
400 & 5 & 2,774 & 1,609 & 516 & 50 & 0 \\
400 & 7 & 214 & 48 & 14 & 0 & 0 \\
600 & 1 & 3,035 & 2,984 & 2,176 & 418 & 0 \\
600 & 3 & 2,482 & 1,198 & 361 & 31 & 0 \\
600 & 5 & 85 & 15 & 6 & 0 & 0 \\
600 & 7 & 0 & 0 & 0 & 0 & 0 \\
\hline
\end{tabular}

Extended Data Fig. 2 | Validation of SMDW using household surveys

reporting SMDW at household-level. (a) Charted and (b) tabulated validation of cross-estimation of percentage safely managed (SM) from at least basic (ALB) drinking water ladders at sub-national (SN) level from national (N) breakdowns using known reference data set at SN level from WHO/UNICEF JMP data. Reference values from nationally representative Multiple Indicator Cluster Surveys integrating water quality testing (ref. SM) compared with our estimates from the JMP Geoprocessor combining JMP sub-national estimates for ALB and national estimates for safely managed drinking water services (est. $\mathrm{SM})$. Ordinary least squares regression (OLS) resulted in standard error (stdErr) as reported. Sample size $n=15$. Table (b) shows main results (ERA5-Land) population counts after adjustment from regression. Population without safely managed drinking water (SMDW) shown across global horizontal irradiance $(G H I)$ and relative humidity $(r H)$ thresholds. 


\section{Article}

P90 30-day overall mean

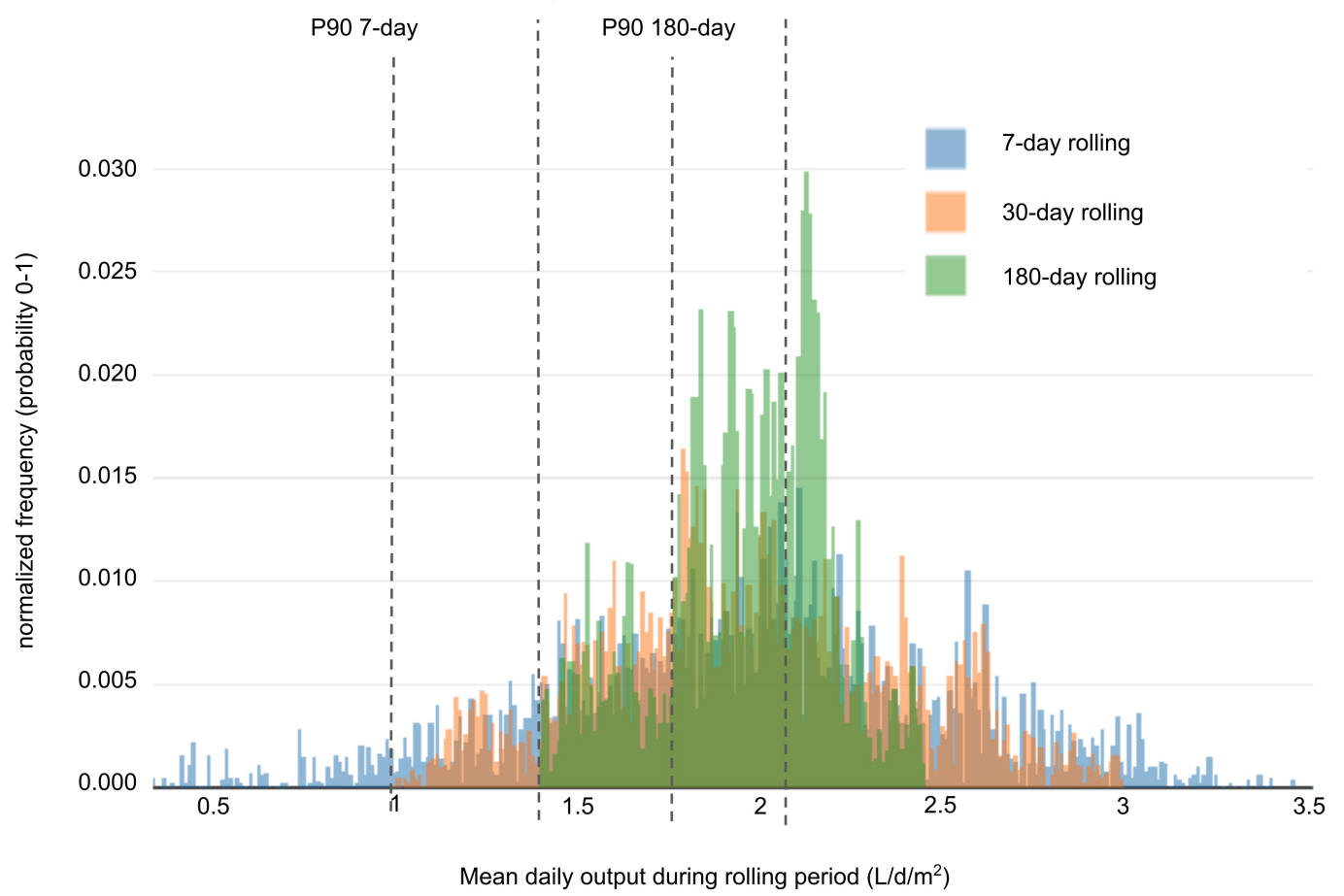

Extended Data Fig. 3 | Visual representation of MADP90 concept from location in Tanzania. Histograms of moving-averaged output $\left(\mathrm{L} / \mathrm{d} / \mathrm{m}^{2}\right)$ across window periods (indicated in days) for a location in Manda, Tanzania. P90 availability value increases as averaging window period increases. $P 90$ values are estimated and for illustrative purposes only. 

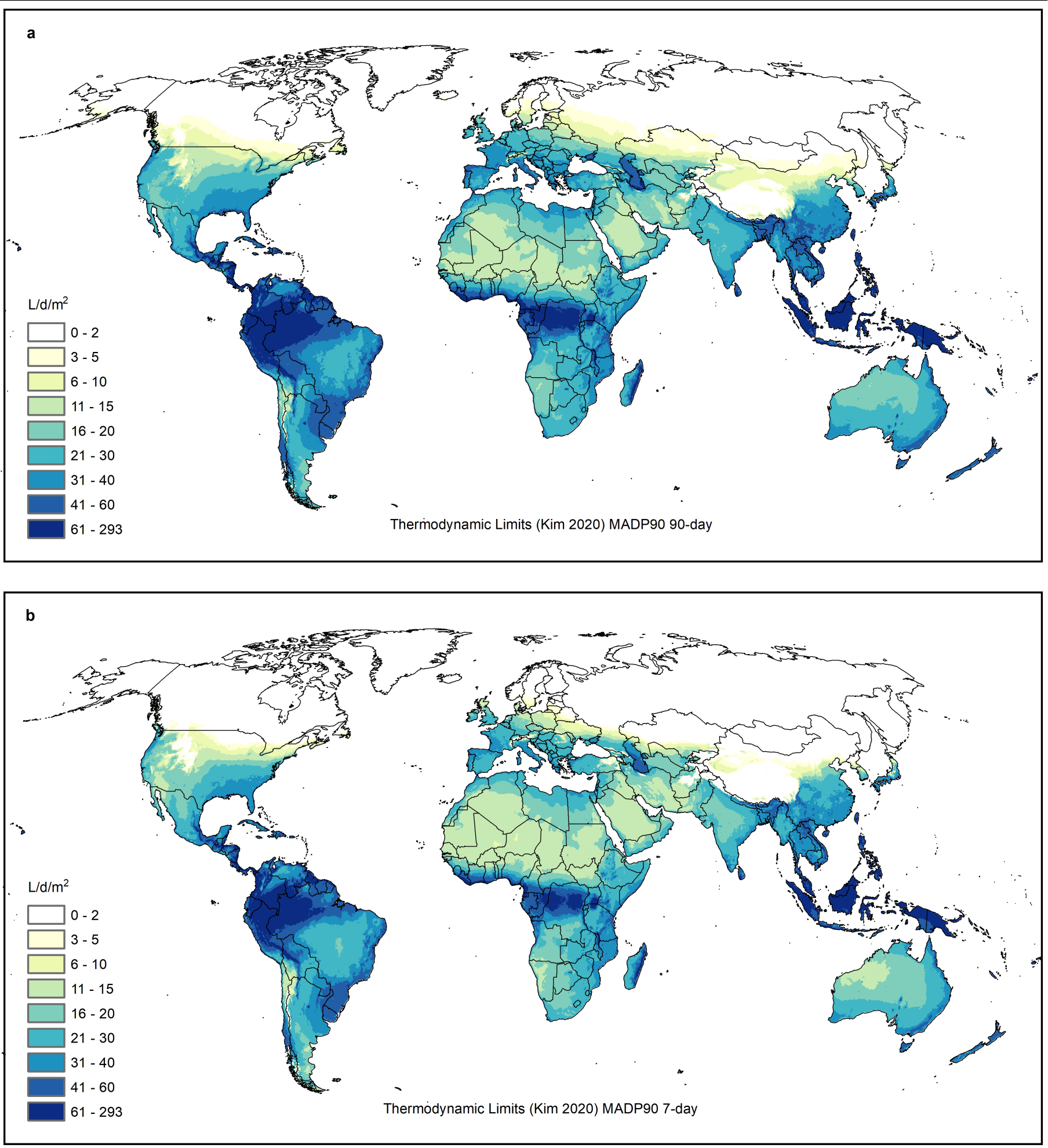

Extended Data Fig. 4 | Select MADP90 metrics of AWH upper bounds. (a) MADP90-90day, and (b) MADP90-7day values (measure of availability through time) globally for AWH thermodynamic upper bounds (Kim 2020), during ten year 2010-2019 (inclusive) analysis period. 


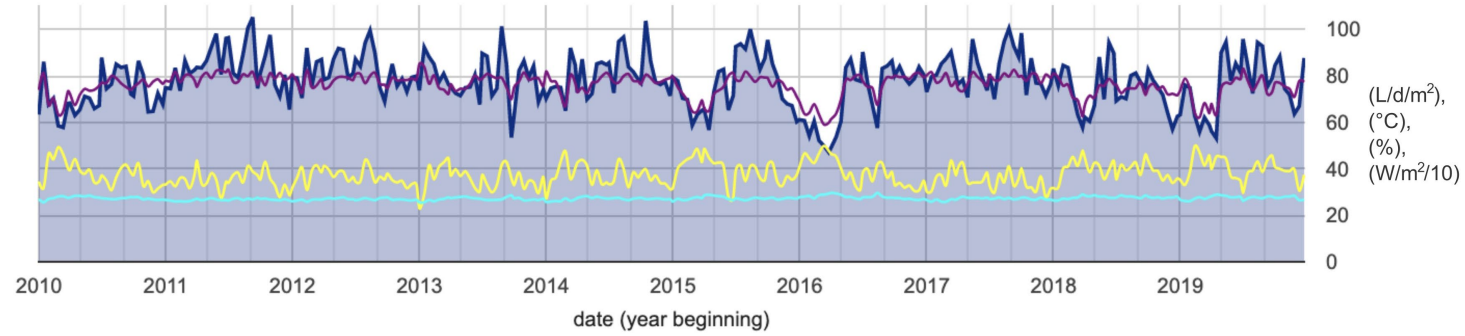

b

Limits_Kim2020 timeseries

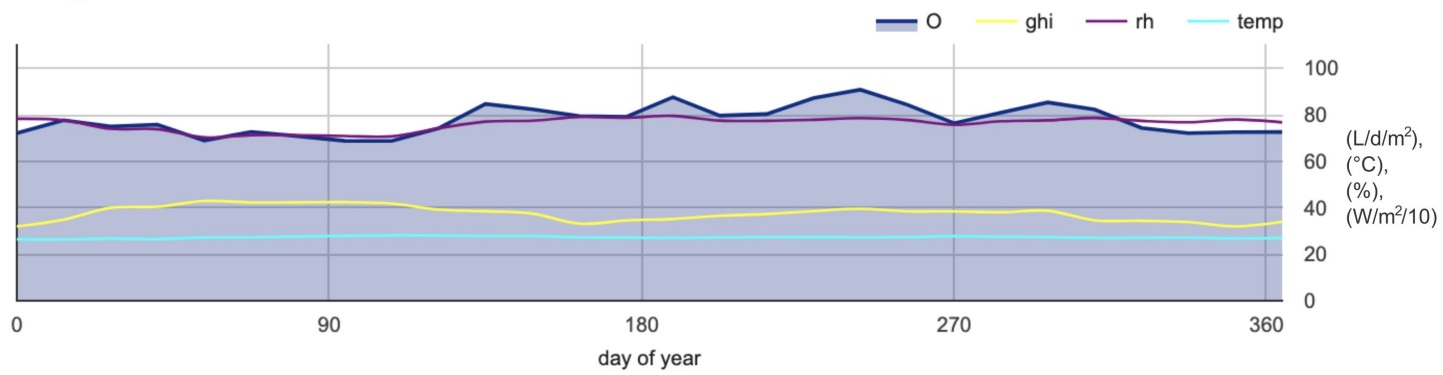

C

1.0 billion Target Curve (linear) timeseries
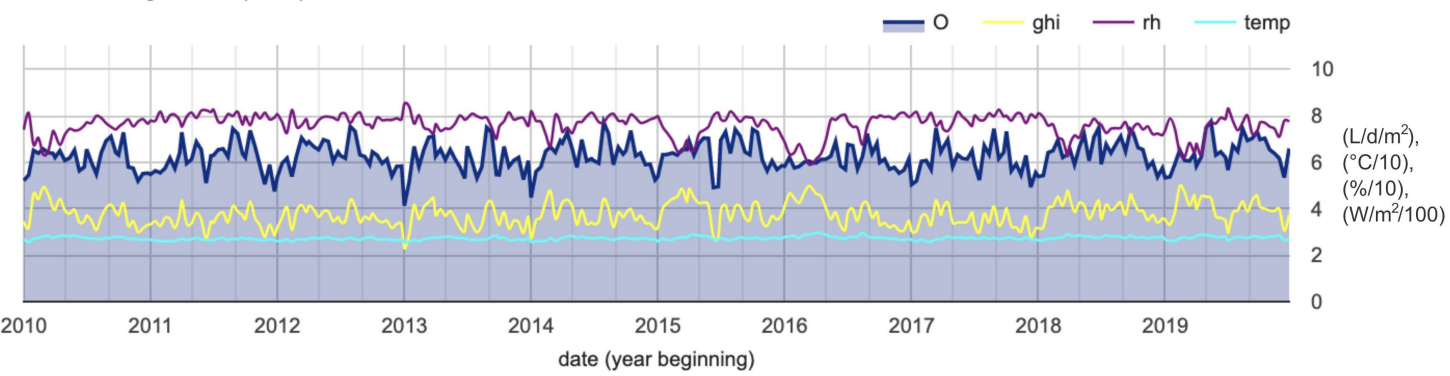

Extended Data Fig. 5 | Bi-weekly timeseries of AWH output and climate drivers for equatorial profile in Davao, Philippines. Bi-weekly mean output $\left(\mathrm{L} / \mathrm{d} / \mathrm{m}^{2}\right)$, and climate inputs global horizontal irradiance $(\mathrm{GHI}$, plotted from $\left.0-1000 \mathrm{~W} / \mathrm{m}^{2}\right)$, relative humidity $(\mathrm{rH}$, plotted from $0-100 \%)$, and temperature (plotted from $0-100^{\circ} \mathrm{C}$ ) of (a) AWH thermodynamic upper bounds (Kim 2020) during ten year 2010-2019 (inclusive) analysis period for each bi-weekly interval and (b) averaged by bi-weekly period annually during this period, and (c) for the 1 billion user linear target curve for each bi-weekly interval. Example of a steady, low variability output profile characteristic of equatorial tropics. 


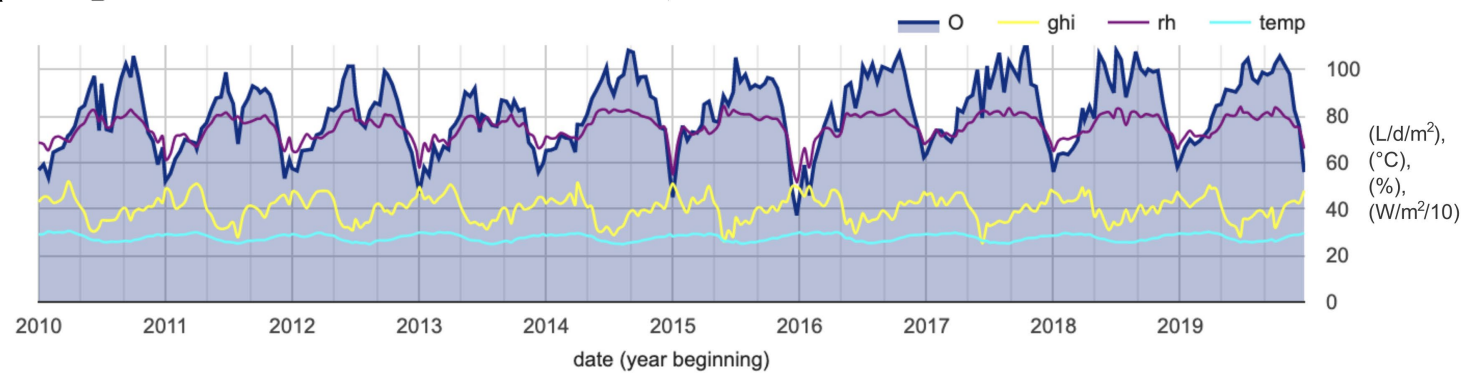

b

Limits_Kim2020 timeseries

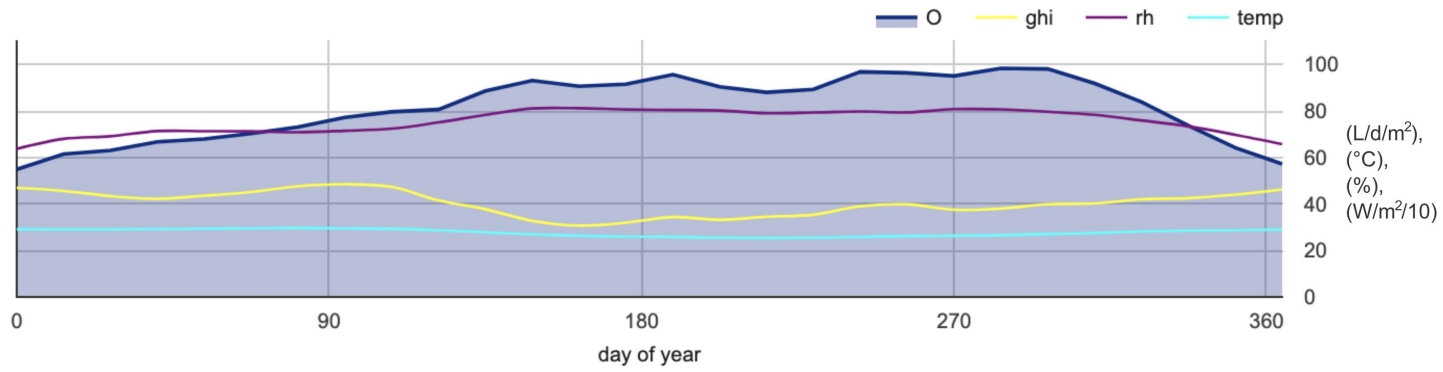

c

1.0 billion Target Curve (linear) timeseries
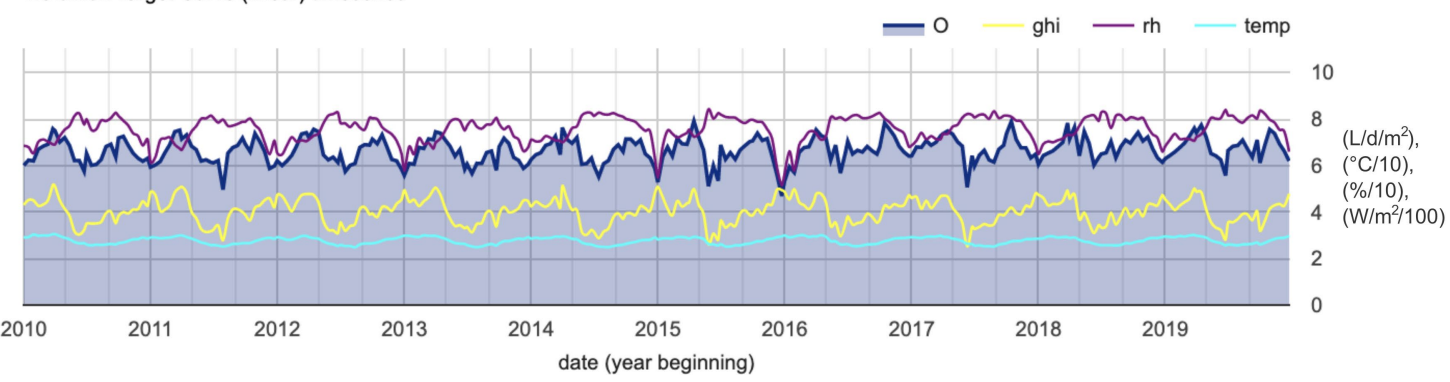

Extended Data Fig. 6 | Bi-weekly timeseries of AWH output and climate drivers for tropical savanna profile in Accra, Ghana. Bi-weekly mean output $\left(\mathrm{L} / \mathrm{d} / \mathrm{m}^{2}\right)$, and climate inputs global horizontal irradiance $(G H I$, plotted from $\left.0-1000 \mathrm{~W} / \mathrm{m}^{2}\right)$, relative humidity $(\mathrm{rH}$, plotted from $0-100 \%)$, and temperature (plotted from $0-100^{\circ} \mathrm{C}$ ) of (a) AWH thermodynamic upper bounds (Kim 2020) during ten year 2010-2019 (inclusive) analysis period for each bi-weekly interval and (b) averaged by bi-weekly period annually during this period, and (c) for the 1billion user linear target curve for each bi-weekly interval. Example of a seasonal wet-dry tropical savanna climate with moderate semi-annual fluctuations of AWH output driven by $\mathrm{rH}$. 


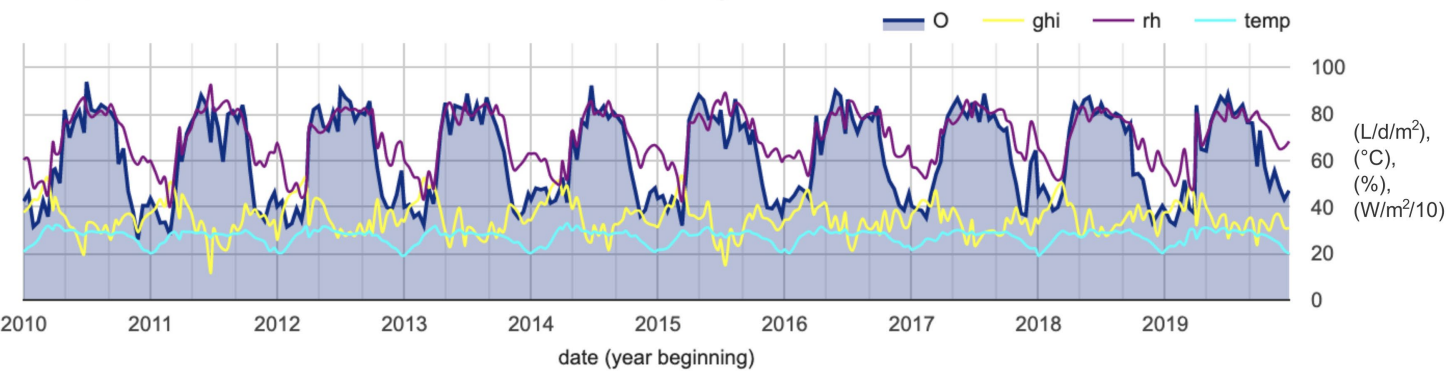

b

Limits_Kim2020 timeseries

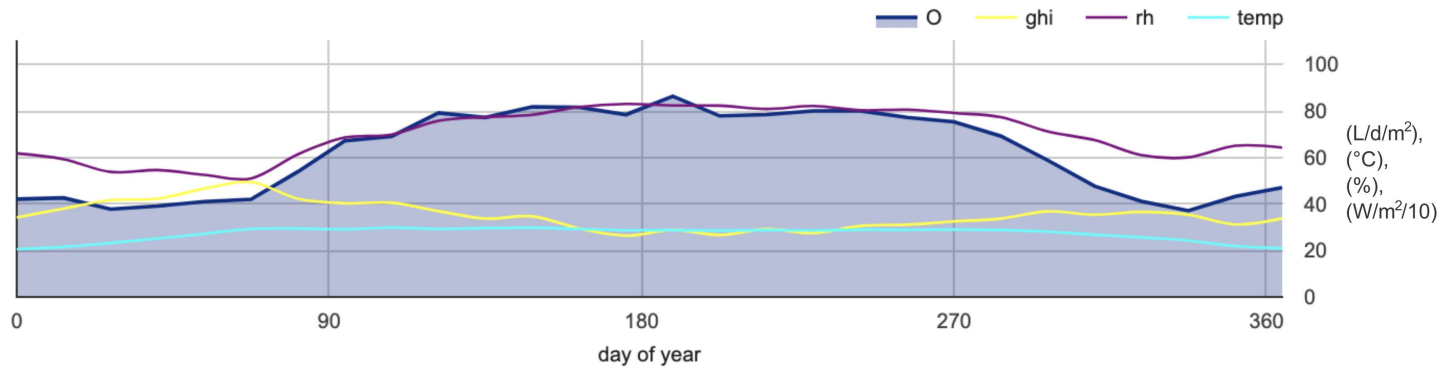

C

1.0 billion Target Curve (linear) timeseries

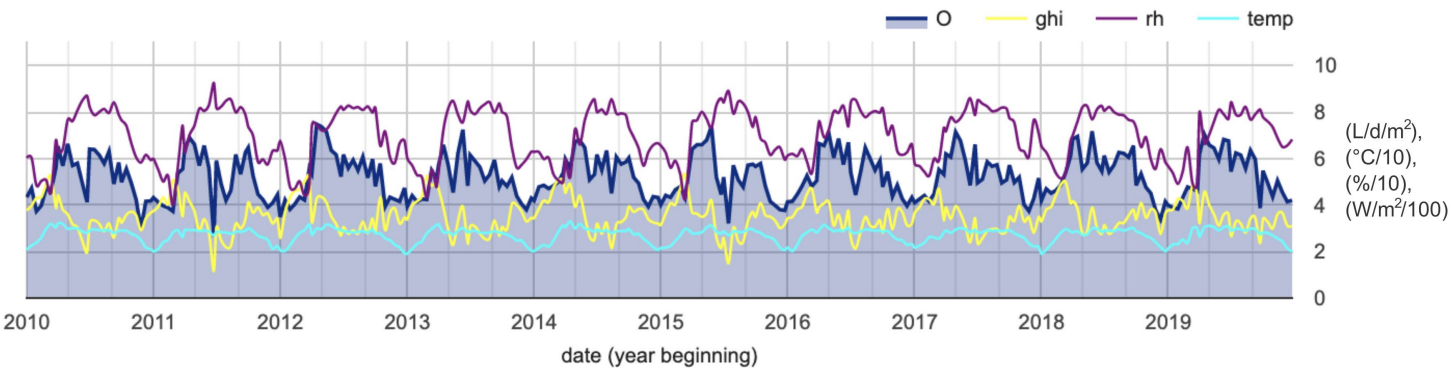

Extended Data Fig. 7 | Bi-weekly timeseries of AWH output and climate drivers for tropical savanna profile in Dhaka, Bangladesh. Bi-weekly mean output $\left(\mathrm{L} / \mathrm{d} / \mathrm{m}^{2}\right)$, and climate inputs global horizontal irradiance $(\mathrm{GHI}$, plotted from $\left.0-1000 \mathrm{~W} / \mathrm{m}^{2}\right)$, relative humidity $(\mathrm{rH}$, plotted from $0-100 \%)$, and temperature (plotted from $0-100^{\circ} \mathrm{C}$ ) of (a) AWH thermodynamic upper bounds (Kim 2020) during ten year 2010-2019 (inclusive) analysis period for each bi-weekly interval and (b) averaged by bi-weekly period annually during this period, and (c) for the 1 billion user linear target curve for each bi-weekly interval. Example of a seasonal wet-dry tropical savanna climate with pronounced semi-annual fluctuations of AWH output driven by $\mathrm{rH}$. 


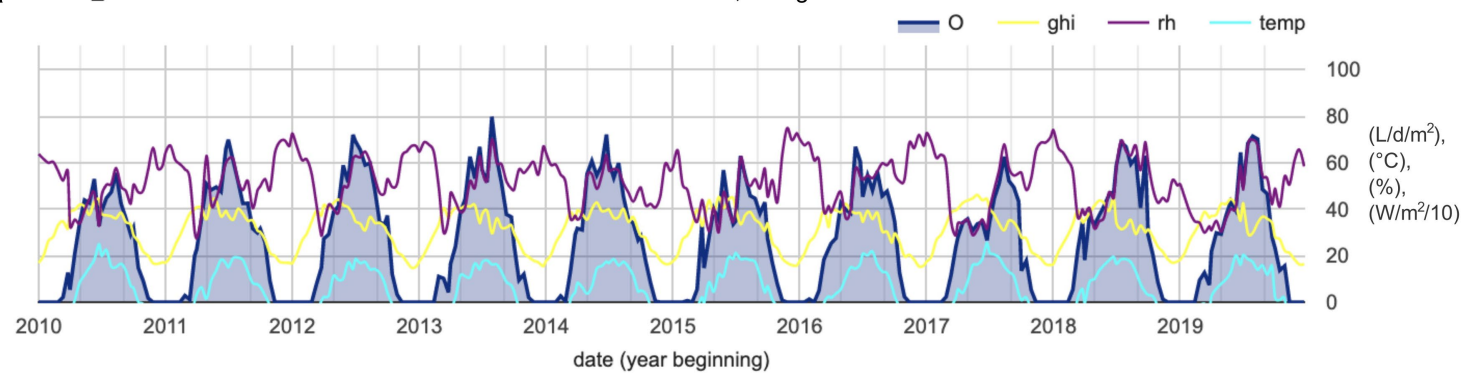

b

Limits_Kim2020 timeseries

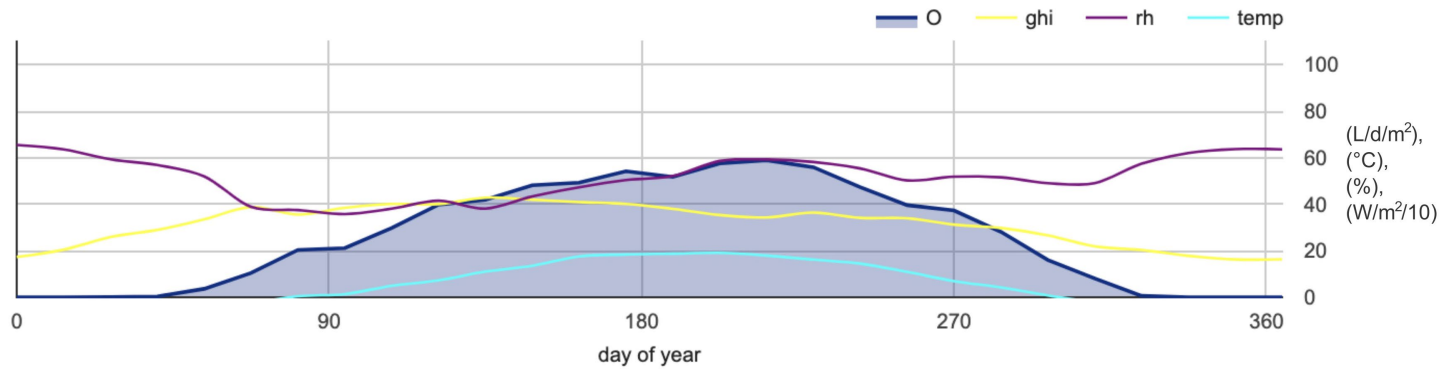

C

1.0 billion Target Curve (linear) timeseries

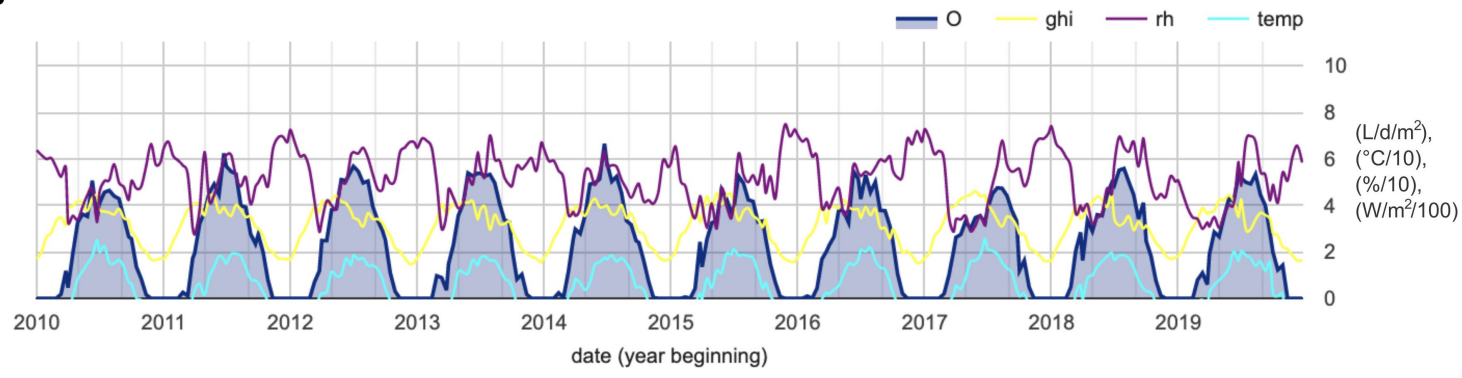

Extended Data Fig. 8 | Bi-weekly timeseries of AWH output and climate drivers for mid-latitude profile in Ulaanbaatar, Mongolia. Bi-weekly mean output $\left(\mathrm{L} / \mathrm{d} / \mathrm{m}^{2}\right)$, and climate inputs global horizontal irradiance $(\mathrm{GHI}$, plotted from $\left.0-1000 \mathrm{~W} / \mathrm{m}^{2}\right)$, relative humidity $(\mathrm{rH}$, plotted from $0-100 \%)$, and temperature (plotted from $0-100^{\circ} \mathrm{C}$ ) of (a) AWH thermodynamic upper bounds (Kim 2020) during ten year 2010-2019 (inclusive) analysis period for each bi-weekly interval and (b) averaged by bi-weekly period annually during this period, and (c) for the 1 billion user linear target curve for each bi-weekly interval. Example of a mid-latitude climate with pronounced semi-annual fluctuations of AWH output driven by temperature. 


\section{Article}
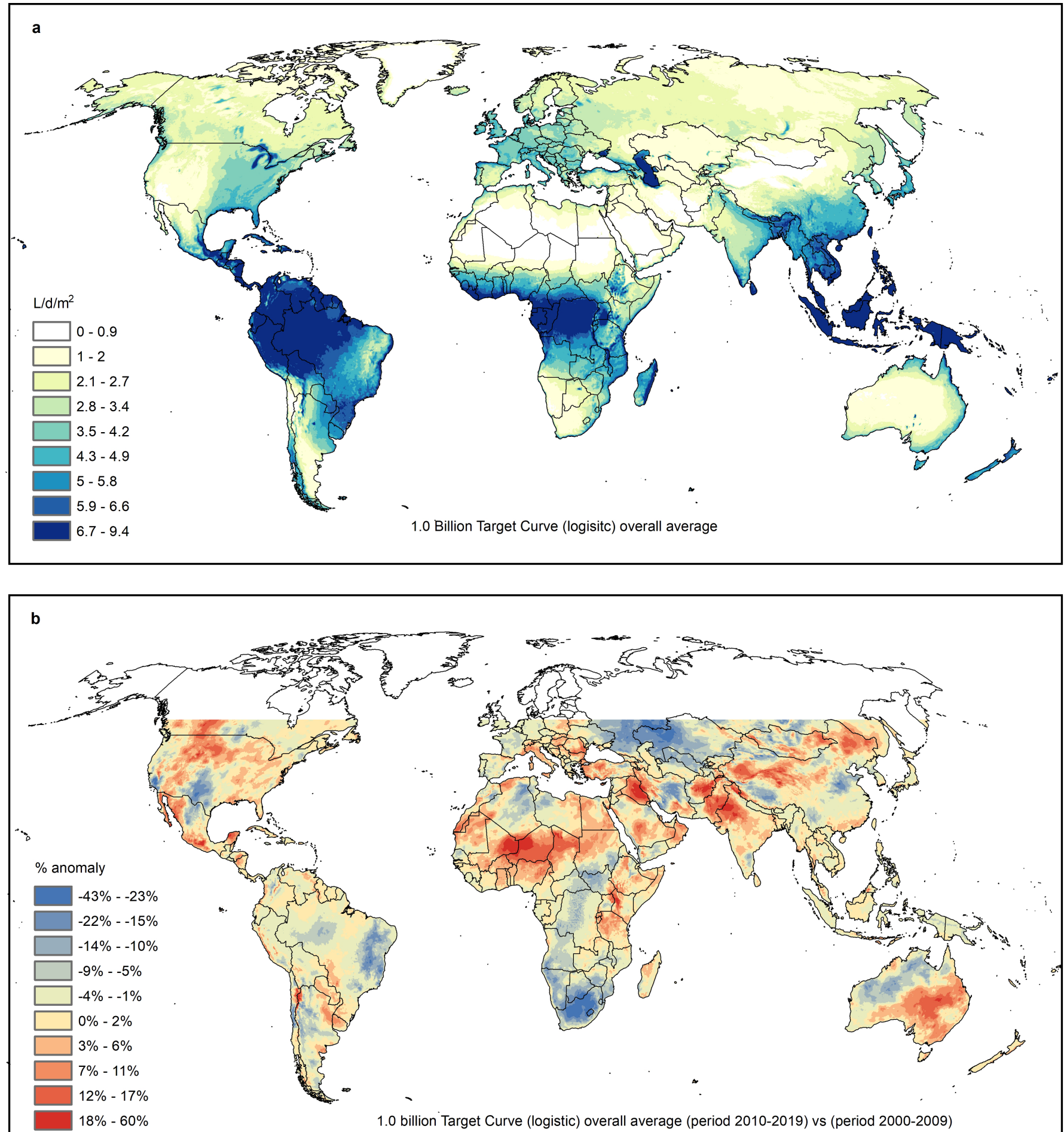

Extended Data Fig. 9 |Decadal anomaly of AWH output with logistic $S Y$ profile between 2000-2009 and 2010-2019. (a) Overall mean output $\left(\mathrm{L} / \mathrm{d} / \mathrm{m}^{2}\right)$ of 1 billion user target logistic curve at $5 \mathrm{~L} / \mathrm{d} / \mathrm{m}^{2}$ during ten year $2010-2019$ (inclusive) period. (b) Ratio (\%) anomaly of output of same specific yield
( $S Y$, in L/kWh) profile averaged over ten year 2000-2009 (inclusive) period. Red colors indicate increasing AWH output with time between the two decades. Blue colors indicate decreasing AWH output. 